\title{
INHIBITION OF CYCLOOXYGENASE-2 IMPACTS CHONDROCYTE HYPERTROPHIC DIFFERENTIATION DURING ENDOCHONDRAL OSSIFICATION
}

\author{
T.J.M. Welting ${ }^{1 *}$, M.M.J. Caron ${ }^{1}$, P.J. Emans ${ }^{1}$, M.P.F. Janssen ${ }^{1}$, K. Sanen ${ }^{1}$, M.M.E. Coolsen ${ }^{1}$, L. Voss ${ }^{1}$, \\ D.A.M. Surtel ${ }^{1}$, A. Cremers ${ }^{1}$, J.W. Voncken ${ }^{2 \#}$ and L.W. van Rhijn ${ }^{1 \#}$
}

\author{
${ }^{1}$ Department of Orthopaedic Surgery, CAPHRI School for Public Health and Primary Care, Maastricht University \\ Medical Center, The Netherlands \\ ${ }^{2}$ Department of Molecular Genetics, GROW School for Oncology and Developmental Biology, Maastricht University \\ Medical Center, The Netherlands
}

\#These authors contributed equally to the manuscript

\begin{abstract}
Skeletogenesis and bone fracture healing involve endochondral ossification, a process during which cartilaginous primordia are gradually replaced by bone tissue. In line with a role for cyclooxygenase-2 (COX-2) in the endochondral ossification process, non-steroidal anti-inflammatory drugs (NSAIDs) were reported to negatively affect bone fracture healing due to impaired osteogenesis. However, a role for COX-2 activity in the chondrogenic phase of endochondral ossification has not been addressed before. We show that COX-2 activity fulfils an important regulatory function in chondrocyte hypertrophic differentiation. Our data reveal essential cross-talk between COX-2 and bone morphogenic protein-2 (BMP-2) during chondrocyte hypertrophic differentiation. BMP-2 mediated chondrocyte hypertrophy is associated with increased COX-2 expression and pharmacological inhibition of COX-2 activity by NSAIDs (e.g., Celecoxib) decreases hypertrophic differentiation in various chondrogenic models in vitro and in vivo, while leaving early chondrogenic development unaltered. Our findings demonstrate that COX-2 activity is a novel factor partaking in chondrocyte hypertrophy in the context of endochondral ossification and these observations provide a novel etiological perspective on the adverse effects of NSAIDs on bone fracture healing and have important implications for the use of NSAIDs during endochondral skeletal development.
\end{abstract}

Keywords: Stem cells, chondrogenesis, growth factors, COX-2 inhibition, chondrocyte hypertrophy, endochondral ossification.

\footnotetext{
*Address for correspondence:

Tim J.M. Welting

Department of Orthopaedic Surgery

Maastricht University Medical Center

P.O. Box 5800, 6202 AZ Maastricht

The Netherlands
}

Telephone Number: +31-43-3884157

FAX Number: +31-43-3874893

E-mail: t.welting@maastrichtuniversity.nl

\section{Introduction}

Endochondral ossification is a multistage process that determines the major part of mammalian skeletal development. This process takes place in growth plates of long bones which are populated by highly proliferative chondrocytes, vectorially dictated to differentiate into hypertrophic chondrocytes before dying from apoptosis. The remaining mineralised extra cellular matrix provides a scaffold for infiltrating osteoblasts and osteoclasts to adhere to and remodel, setting the stage for de novo bone deposition (Kronenberg, 2003; Mackie et al., 2008). Chondrocyte hypertrophic differentiation also plays a role in bone fracture healing which reiterates the endochondral ossification process: initial cartilage callus formation by mesenchymal progenitor cells from the local periosteum and bone marrow, followed by chondrocyte hypertrophy and osteogenic mineralisation and remodelling.

Non steroidal anti-inflammatory drugs (NSAIDs) are widely used systemic inhibitors of inflammatory prostaglandin production by cyclooxygenases (COX-1 and COX-2) (Brooks et al., 1999). In orthopaedic surgery the use of NSAIDs is under debate, as systemic NSAID treatment delays spinal fusion in patients and animal models (Thaller et al., 2005) and fracture healing of the long bones (Goodman et al., 2002; Gerstenfeld et al., 2003; Simon and O'Connor, 2007; Herbenick et al., 2008). This property of NSAIDs is, however, exploited in the clinic to prevent periprosthetic heterotopic calcification after hip surgery (Grohs et al., 2007). The action of NSAIDs has been studied in the context of osteogenesis, and several observations link prostaglandin $\mathrm{E}_{2}\left(\mathrm{PGE}_{2}\right)$ and COX-2 to osteoblast differentiation (Zhang et al., 2002; Einhorn, 2003; Arikawa et al., 2004; Xie et al., 2009). Mice lacking the prostaglandin synthesising enzymes COX-2 or mPGES-1 show impaired fracture healing caused by insufficient $\mathrm{PGE}_{2}$ synthesis (Zhang et al., 2002; Yamakawa et al., 2008). Expression of bone morphogenic protein-2 (BMP-2) is regulated by COX-2 activity (Arikawa et al., 2004) and downstream signalling of BMP-2 in osteogenesis involves formation of a RUNX2-SMAD transcription factor complex (Javed et al., 2009). Combined, these data provide insight into the role of COX-2 activity during osteogenesis and suggest a plausible explanation for the adverse effects of NSAIDs on bone healing.

Recently, prostaglandins were shown to influence chondrogenesis in vitro (Jakob et al., 2004). Prostaglandin 
receptors and COX-enzymes localise to the developing growth plate (Brochhausen et al., 2006; Brochhausen et al., 2008) and BMP-2, whose expression depends on COX-2 activity (Arikawa et al., 2004), is described to determine endochondral ossification by regulating chondrocyte differentiation (De Luca et al., 2001). Hypertrophic chondrocytes uniquely express the Collagen type $\mathrm{X}$ alpha-1 chain (COL10A1) (Linsenmayer et al., 1988) whose expression depends, amongst others, on (BMP-2 induced) RUNX2/CBFA1 (Zheng et al., 2003). However, the exact description of a role for COX-2 in chondrogenesis is lacking, and the functional relation between BMP-2, COX-2 and chondrocyte hypertrophic differentiation in the context of endochondral ossification remains unclear at present. We therefore hypothesised that chondrocyte hypertrophic differentiation is determined by BMP-2 via a COX-2 dependent mechanism. The hypothesis was addressed using different models for endochondral ossification. Our results reveal that inhibition of COX-2 activity specifically decreases the level of BMP-2 induced hypertrophic differentiation in endochondral culture models, and systemic inhibition of COX-2 activity in vivo resulted in significantly impaired chondrocyte hypertrophic differentiation in rabbit growth plates.

\section{Materials and Methods}

ATDC5 cell culture and chondrogenic differentiation ATDC5 cells were cultured in proliferation medium (DMEM/F12 (Invitrogen/Life Technologies, Carlsbad, CA, USA), $5 \%$ foetal calf serum (FCS) (PAA, Pasching, Austria), $1 \%$ NEAA (Invitrogen/Life Technologies) and 1 $\%$ antibiotic/antimycotic (Invitrogen/Life Technologies)) (Atsumi et al., 1990). Cells were differentiated in differentiation medium (proliferation medium supplemented with $10 \mu \mathrm{g} / \mathrm{mL}$ insulin (Sigma-Aldrich, St. Louis, MO, USA, I2643), $10 \mu \mathrm{g} / \mathrm{mL}$ transferrin (Roche Applied Science; Basel, Switzerland, 10652202001) and $30 \mathrm{nM}$ Sodium Selenite (Sigma-Aldrich, S9133)). The day prior to differentiation, ATDC5 cells were plated at 6,400 cells $/ \mathrm{cm}^{2}$ in culture dishes and allowed to adhere overnight in proliferation medium. Chondrogenesis was initiated by changing the medium to differentiation medium. Differentiation medium was strictly changed at day 2, 4, 6 and 8 and from day 8 every day. When indicated, BMP2 was used (Wyeth/Pfizer, New York, NY, USA). COX-2 activity was inhibited by NS398 (Cayman Chemicals, Tallinn, Estonia) or Celecoxib (LC Laboratories, Woburn, MA, USA). Phosphorylation of SMAD1/5/8 was inhibited by Dorsomorphin (Santa Cruz, Santa Cruz, CA, USA).

\section{Periosteum agarose culture (PAC) chondrogenic differentiation}

Periosteum was harvested from the proximal tibia of skeletally mature New Zealand white rabbits. Post-mortem control animals were freshly obtained from an unrelated study, no ethical approval was necessary. Periosteum was harvested from these rabbits within 15 min after sacrifice. Presence of the cambium layer was checked by histology. The periosteum was transported in HEPES buffered DMEM/F12 supplemented with antibiotics. Per rabbit, the harvested Periosteum (generally $5 \times 5 \mathrm{~mm}$ ) was prepared as a $3 \times 3 \mathrm{~mm}$ piece using a sterile surgical blade and embedded in 24-well plates using the following procedure adapted from O'Driscoll et al. (O'Driscoll et al., 1994): $250 \mu \mathrm{L} 1 \%$ high melting agarose $/ 0.9 \% \mathrm{NaCl}$ (37 $\left.{ }^{\circ} \mathrm{C}\right)$ was applied on the bottom of the well and allowed to solidify. Periosteum pieces were put on top and allowed to float in $375 \mu \mathrm{L} 1 \%$ low melting agarose $/ 0.9 \% \mathrm{NaCl}$ $\left(37{ }^{\circ} \mathrm{C}\right)$. After solidifying, an additional $375 \mu \mathrm{L} 1 \%$ low melting agarose $/ 0.9 \% \mathrm{NaCl}$ was applied. The agarose was allowed to solidify for an additional $10 \mathrm{~min}$. One $\mathrm{mL}$ of PAC proliferation medium (DMEM/F12, $10 \%$ FCS (PAA), $1 \% \mathrm{P} / \mathrm{S}, 1 \% \mathrm{NEAA}$ ) was added and incubated overnight at $37{ }^{\circ} \mathrm{C} / 5 \% \mathrm{CO}_{2}$. After overnight incubation, medium was changed to PAC differentiation medium (proliferation medium supplemented with $1 \%$ ITS (Invitrogen/Life Technologies), $50 \mu \mathrm{g} / \mathrm{mL}$ L-ascorbic acid-2-phosphate (Sigma-Aldrich), 10 ng/mL TGF $\beta 3$ (R\&D Systems, Minneapolis, MN, USA)). PACs were maintained in differentiation medium by changing medium every 3 days.

\section{Immunoblotting}

After washing with $0.9 \% \mathrm{NaCl}$, ATDC5 cells were lysed in RIPA buffer (150 mM NaCl, $1 \%$ NP-40, 0.5 $\%$ sodium dexoycholate, $0.1 \%$ SDS, $50 \mathrm{mM}$ Tris- $\mathrm{HCl}$ $\mathrm{pH} 8.00,5 \mathrm{mM}$ EDTA, $0.5 \mathrm{mM}$ dithiotreitol, $2 \mathrm{mM}$ phenylmethylsulfonylfluoride) and homogenised on ice by sonication (Soniprep 150, MSE, London, UK). Insoluble material was removed by centrifugation ( 5 min; $13,000 \mathrm{~g} ; 4{ }^{\circ} \mathrm{C}$ ). Total protein concentration was determined using a bicinchoninic acid (BCA) assay (Sigma-Aldrich). Polypeptides were separated by sodium dodecyl sulphate polyacrylamide gel electrophoresis (SDSPAGE) and transferred to nitrocellulose membranes by electroblotting. Immunodetection of COL2A1, COL10A1, GAPDH, RUNX2, pSMAD1/5/8, $\beta$-catenin and COX2 was performed using polyclonal goat and rabbit sera (COL2A1 (SouthernBiotech, Birmingham, AK, USA), COL10A1 (Calbiochem/Merck, Darmstadt, Germany), COX-2 (Oxford Biomedical Research, Rochester Hills, MI, USA), pSMAD1/5/8 (Cell Signaling Technology, Beverly, MA, USA) and mouse monoclonal antibodies recognising GAPDH (Fitzgerald, Acton, MA, USA), $\beta$-catenin (BD Biosciences, Franklin Lakes, NJ, USA) and RUNX2 (MBL International, Des Plaines, IL, USA). Horseradish peroxidase-conjugated immunoglobulins were purchased from DakoCytomation (Dako, Glostrup, Denmark) and applied as secondary antibody. Bound antibodies were visualised by enhanced chemiluminescence detection procedures. Several housekeepers were used to verify total protein loading. However, although equally loaded (quantitatively determined by BCA assay and visually by Ponseau-S (on membrane) and Coomassie Brilliant Blue staining (in gel)), GAPDH, $\alpha$-tubulin and $\beta$-actin protein expression appeared to be regulated during the course of chondrogenesis. However, these protein housekeepers were stable amongst different samples from the same chondrogenic differentiation stage (e.g., day 14). 
Table 1. Primer sequences for RTqPCR

\begin{tabular}{|l|c|c|c|}
\cline { 2 - 4 } \multicolumn{1}{c|}{} & species & forward sequence & reverse sequence \\
\hline COL2A1 & mouse/rabbit & TGGGTGTTCTATTTATTTATTGTCTTCCT & GCGTTGGACTCACACCAGTTAGT \\
\hline COL10A1 & mouse & CATGCCTGATGGCTTCATAAA & AAGCAGACACGGGCATACCT \\
\hline COL10A1 & rabbit & AACCTGGACAACAGGGACTTACA & CCATATCCTGTTTCCCCTTTCTG \\
\hline$\beta$-actin & mouse/rabbit & GACAGGATGCAGAAGGAGATTACTG & CCACCGATCCACACAGAGTACTT \\
\hline BMP-2 & mouse & AGAAAAGCGTCAAGCGAAACA & GTCCACGTACAAAGGGTGTCTCT \\
\hline COX-1 & mouse & TCCTCACAGTGCGGTCCAA & AAGGCCTCCCAGCTGATGTAG \\
\hline COX-2 & mouse/rabbit & ACCAACATGATGTTTGCATTCTTT & GGTCCCCGCTTAAGATCTGTCT \\
\hline RUNX2 & mouse & GACGAGGCAAGAGTTTCACC & GGACCGTCCACTGTCACTTT \\
\hline MEF2C & mouse & GGGCCTCAATGGCTGTGA & CTCAGACTCAGGGCTGTGACCTA \\
\hline MMP13 & mouse & CGATGAAGACCCCAACCCTAA & ACTGGTAATGGCATCAAGGGATA \\
\hline VEGF-a & mouse & GTCAGAGAGCAACATCACCA & CATCTGCTGTGCTGTAGGAA \\
\hline ALP & mouse & CCGATGGCACACCTGCTT & GGAGGCATACGCCATCACAT \\
\hline
\end{tabular}

The 5' to 3' forward and reverse oligonucleotide sequences used for RT-qPCR are listed in the Table. Exchangeability between mouse and rabbit is mentioned when applicable.

\section{Real time quantitative PCR (RT-qPCR)}

To isolate total RNA from PAC cultures, tissue was cut in pieces and soaked overnight in $500 \mu \mathrm{L}$ Trizol (Invitrogen/ Life Technologies) at $4{ }^{\circ} \mathrm{C}$. For RNA isolation from ATDC5 cells, cells were washed with $0.9 \% \mathrm{NaCl}$ and disrupted with $500 \mu \mathrm{L}$ Trizol. Total RNA from the aqueous phase was precipitated by using isopropanol and centrifugation (13.000 g; $30 \mathrm{~min} ; 4^{\circ} \mathrm{C}$ ). Pellets were washed with $80 \%$ ethanol, allowed to airdry and dissolved in DEPC-treated water. Genomic DNA was removed by DNase I (Roche) treatment $\left(20 \mathrm{U} ; 1 \mathrm{~h} ; 37^{\circ} \mathrm{C}\right)$. RNA was precipitated with $\mathrm{NaAc} /$ ethanol and subsequent centrifugation. Pellets were washed with $80 \%$ ethanol and allowed to airdry. Purified RNA was dissolved in $20 \mu \mathrm{L}$ DEPC-treated water and analysed spectrophotometrically (Nanodrop, Thermo Scientific, Waltham, MA, USA). For cDNA synthesis, 200 ng total RNA was used in a $25 \mu \mathrm{L}$ standard RT-reaction containing 1x RT-buffer (Promega, Madison, WI, USA); $2 \mathrm{ng} / \mu \mathrm{L}$ random primer (Promega); $0.5 \mathrm{mM}$ per $\mathrm{dNTP}$ (Eurogentec, Liège, Belgium); $10 \mathrm{mM}$ dithiotreitol; $0.4 \mathrm{U} / \mu \mathrm{L}$ RNasin (Promega); $4 \mathrm{U} / \mu \mathrm{L}$ M-MLV reverse transcriptase (Promega).

Real time qPCR was performed in triplicate with Mesagreen qPCR mastermix plus for SYBR ${ }^{\circledR}$ Green (Eurogentec) in 96-well optical plates according to the manufacturer's protocol. Forward and reverse primers were used at $300 \mathrm{nM}$ each. Gene expression was determined using an ABI PRISM $® 7700$ Sequence Detection System (Applied Biosystems, Foster City, CA, USA). Serially diluted standard curves were included to quantify the samples. Samples were heated for $10 \mathrm{~min}$ at $95{ }^{\circ} \mathrm{C}$ and DNA was amplified by 40 cycles of $15 \mathrm{~s} 95^{\circ} \mathrm{C}$ and $1 \mathrm{~min}$ $60{ }^{\circ} \mathrm{C}$, followed by a melting curve. Data were analysed using Sequence Detection Software version 1.7 (Applied Biosystems) using the standard curve method. Values were normalised to $\beta$-actin (in contrast to $\beta$-actin protein levels, $\beta$-actin mRNA levels are stable during chondrogenesis). The primer sequences for detection of COL2A1, COL10A1, $\beta$-actin, BMP-2, RUNX2, MEF2C, MMP13, VEGF-a, COX-2 and ALP were based on the coding sequences of the respective mRNAs. The sequences are listed in Table 1 . Values were normalised to $\beta$-actin mRNA levels and fold increase gene expression was calculated relatively to the mean expression value at day 0 in differentiation.

\section{PGE $_{2}$ measurement}

Inhibition of COX-2 activity was determined by measuring prostaglandin $\mathrm{E} 2\left(\mathrm{PGE}_{2}\right)$ in culture medium or blood plasma. $\mathrm{PGE}_{2}$ concentration was determined by a standardised EIA according to the manufacturers' protocol (Cayman Chemical).

\section{Alkaline phosphatase activity}

Enzymatic activity of Alkaline Phosphatase (ALP) in ATDC5 cultures was determined using a colorimetric assay. Cells were lysed in freshly prepared collection buffer (1.5 M Tris-HCl pH 9.0; 2 \% (v/v) Triton X-100) and homogenised on ice by sonication (Soniprep 150, MSE). Insoluble material was removed by centrifugation (5 min; 13,000 g; $4{ }^{\circ} \mathrm{C}$ ). Total protein concentration was determined using a BCA assay (Sigma-Aldrich). In flat bottom 96 well plates, containing assay buffer $(1.5 \mathrm{M}$ Tris- $\mathrm{HCl} \mathrm{pH} 9.0 ; 1 \mathrm{mM} \mathrm{ZnCl} ; 1 \mathrm{mM} \mathrm{MgCl}$; $7.5 \mathrm{mM}$ p-nitrophenyl phosphate), ALP activity was determined by measuring ALP-depend enzymatic conversion of p-nitrophenyl phosphate to nitrophenyl phosphate by spectrophotometrical analyses at $405 \mathrm{~nm}$. A calibration curve containing an increasing concentration of nitrophenyl phosphate was used to determine the absolute amount of ALP-generated nitrophenyl phosphate in time. Values were normalised to total protein concentration and expressed as Units ALP activity ( $1 \mathrm{U}=1 \mu \mathrm{mol}$ nitrophenyl phosphate/ $\mathrm{min} / \mathrm{g})$.

\section{Cell proliferation}

Growth curves for ATDC5 cells were generated by determining DNA content using X-violet. Cells were fixated with $4 \%$ paraformaldehyde in phosphate buffered saline for $10 \mathrm{~min}$ at room temperature. After washing, cells were air dried for further analysis. Fixed 
cells were incubated with $0.1 \% \mathrm{X}$-violet for $30 \mathrm{~min}$ at room temperature. Cells were washed with water to remove excess X-violet and allowed to air-dry in the dark overnight. X-violet was extracted by incubation with $10 \%$ acetic acid for 15 min under continuous agitation. Extracted $\mathrm{X}$-violet was determined spectrophotometrically at 590 nm using a plate reader (Biorad, Hemel Hempstead, UK).

\section{(Immuno)histochemistry}

PAC tissue samples or mouse growth plates were decalcified in formalin/EDTA, dehydrated following standard procedures and embedded in paraffin. Tissue sections were cut at $5 \mu \mathrm{m}$ and positioned on Superfrost Plus slides (Menzel/Thermo Scientific). Before histochemistry, tissue sections on slides were deparafinised and rehydrated using standard protocols. Proteoglycans were stained with Safranin-O (0.1\%) and counterstained with Fast Green $(0.1 \%)$. Stained sections were dehydrated and mounted in Histomount (Thermo Shandon, Runcorn, Cheshire, UK) for microscopic analysis.

For immunohistochemical analysis of RUNX2, COL2A1, COL10A1 and ALP in PAC sections, rehydrated sections were treated with $0.4 \%$ hyaluronidase (COL2A1 and COL10A1 only). Endogenous peroxidase activity was inactivated by Peroxidase-Blocking solution (Dako, REAL) and samples were blocked with $5 \%$ skim milk (RUNX2), $10 \%$ normal sheep serum (COL2A1 and COL10A1) or $10 \%$ normal rabbit serum (ALP) for $30 \mathrm{~min}$. Anti-CBFA1/RUNX2 monoclonal antibody (MBL) was used at 1:700. Mouse monoclonal anti-COL2A1 (II-II6B3; Developmental Studies Hybridoma Bank, Iowa City, IA, USA) and mouse negative control IgG1 (Dako) were used at 1:50 and same IgG1 concentration, respectively. Rabbit polyclonal anti-COL10A1 and negative control non-immune rabbit serum were used at 1:1000. Goat polyclonal affinity purified anti-ALP IgG (R\&D systems) and negative control non-immune goat total IgG (protein-G purified) were used at 1:50 and same IgG concentration, respectively. Primary antibodies were incubated for $1 \mathrm{~h}$ at room temperature. Unbound antibodies were removed by washing with TBS-T. For RUNX2 detection sheep-antimouse-biotin (Amersham Biosciences, Amersham, UK) was used as secondary antibody at 1:200 and incubated for $1 \mathrm{~h}$ at room temperature in TBS/BSA. Sections were washed with TBS-T and Biotin conjugate was detected with SA-HRP (Beckman Coulter, Woerden, The Netherlands) at 1:500 in TBS/BSA and DAB chromogen (Dako). For COL2A1 and COL10A1 bound antibodies were visualised with HRP labelled anti-rabbit or anti-mouse secondary antibodies (Dako, EnVision+ System-HRP labelled Polymer) by incubation for $30 \mathrm{~min}$ at room temperature. Unbound antibodies were removed by rinsing in PBS-T. For ALP detection bound primary antibodies were detected by 1:500 diluted HRP labelled rabbit-anti-goat secondary antibodies (Dako). For detection, DAB chromogen substrate (Dako) was used. Stained sections were mounted in Histomount as described above. In mouse growth plates from 6 week old mice (MUMC animal ethical committee approval ID: DEC 2008-042) COX-2 was detected using citrate-mediated antigen retrieval and 1:50 anti-COX-2 monoclonal antibody (BD Biosciences). Mouse negative control IgG1 (Dako) was used at same concentration. Detection of COL10A1 and ALP in these growth plates was carried out as described above for the PAC sections. Visualisation of anti-COX-2, anti-COL10A1 and anti-ALP primary antibodies was performed as described above.

\section{Celecoxib treatment of rabbits and analysis of growth plates}

The experiment was approved by the Maastricht University animal ethical committee (DEC 2010-027-g). Celecoxib $(10 \mathrm{mg} / \mathrm{kg}$ ) (Pfizer) was orally administered to skeletally immature New Zealand white rabbits (107 days old) for 21 days on a daily basis in $1 \mathrm{~mL}$ Critical Care-paste (Oxbow Animal Health, Murdock, NE, USA). Control animals received $1 \mathrm{~mL}$ paste only. The groups consisted of 6 control animals and 7 Celecoxib-treated animals. Rabbits were euthanised after 3 weeks by an overdose of pentobarbital. The left ulnas were isolated and fixated in formalin. Growth plates were decalcified in $0.5 \mathrm{M}$ EDTA pH 7.8 for 3 weeks. After that growth plates were briefly $(20 \mathrm{~h})$ incubated in 1:5 diluted TBD-1 Rapid Decalcifier (Thermo Shandon). Growth plates were cut in two halves perpendicular to the growth plate plane, dehydrated and embedded in paraffin. From the anterior half, $5 \mu \mathrm{m}$ sections were cut. Sections where stained with haematoxylin and further processed for microscopic analysis using a Zeiss Axioscope A.1 (with AxioVision 4.8 software). The anatomical middle of the growth plates was used as an internal reference point. From each growth plate 3 consecutive sections were measured at both sides at half the distance from the anatomical reference point. At this point a standardised box with a width of $250 \mu \mathrm{m}$ was defined that fitted an average number of 10 chondrocyte columns. Within the box the lengths of the proliferative and hypertrophic zones were determined by three independent blinded observers.

\section{Statistics}

Statistical analyses on the rabbit growth plates were performed as follows. Measurements from consecutive sections and both sides of the same growth plate were averaged. Data of the control (6 rabbits) and Celecoxib (7 rabbits) groups were tested for statistical significance using SPSS (Chicago, IL, USA) 16.0 software. Normal distribution of the data was confirmed by a Shapiro-Wilk normality test and subsequently the significance of the total length of the growth plates, length of the proliferative zone, length of the hypertrophic zone and the ratio between the proliferative and hypertrophic zone were determined using Mann-Whitney tests. A $p<0.05$ was defined as significant. Next to the above statistics, other statistical calculations were determined by unpaired two-tailed Student's $t$-tests using Graphpad (La Jolla, CA, USA) PRISM 5.0. A $p$ $<0.05$ was defined as significant. To test for normal distribution of the input data, D'Agostino-Pearson omnibus normality tests were performed. All quantitative data sets presented here passed the normality tests. 
A

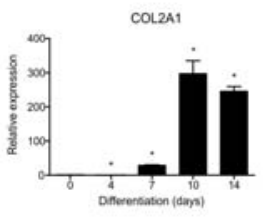

C

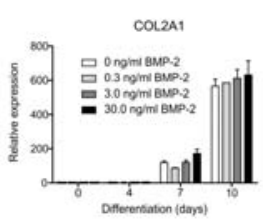

$\mathrm{E}$

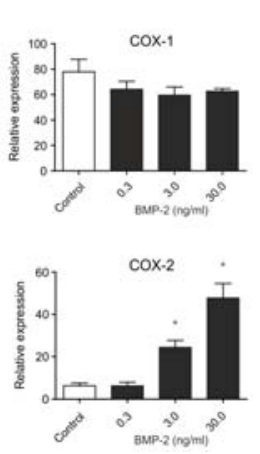

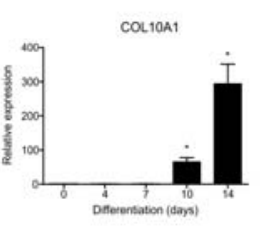
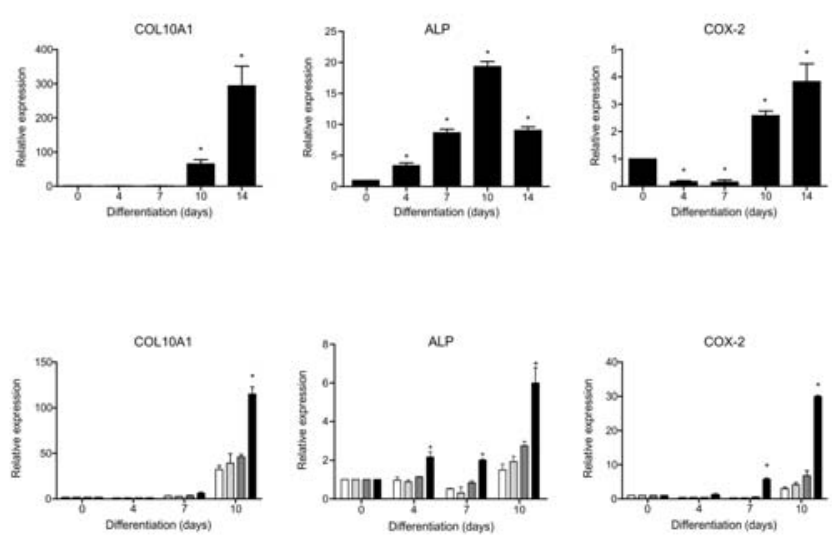

$\mathrm{F}$

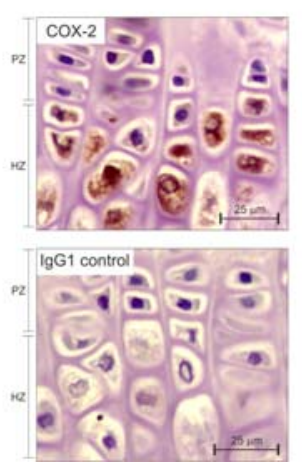

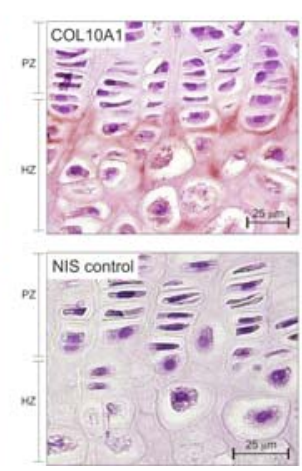

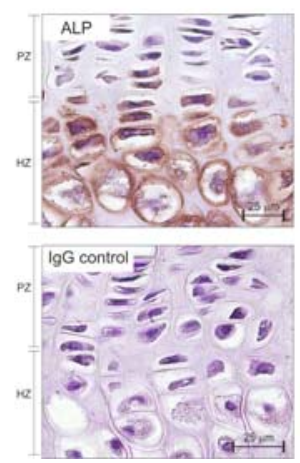

B

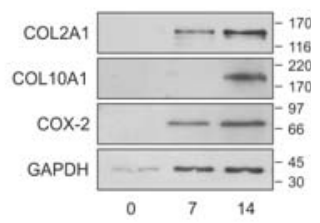

D

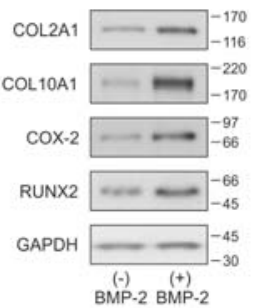

Fig. 1. COX-2 expression and BMP-2 responsiveness during chondrogenic differentiation. Differentiated ATDC 5 cells were harvested at day $0,4,7,10$ or 14. (A) Induction of COL2A1, COL10A1, ALP and COX-2 mRNA expression was determined by RT-qPCR. $N=9$ for each time point. Error bars represent mean \pm s.d.. (B) COL2A1, COL10A1 and COX-2 protein expression at 0,7 and 14 days after initiation of differentiation. GAPDH was used as housekeeper. Molecular weight markers $(\mathrm{kDa})$ are depicted on the right. (C) BMP-2 was added to differentiation medium at $0 \mathrm{ng} / \mathrm{mL}$ (white bars), $0.3 \mathrm{ng} / \mathrm{mL}$ (light grey bars), $3.0 \mathrm{ng} / \mathrm{mL}$ (dark grey bars) or $30 \mathrm{ng} / \mathrm{mL}$ (black bars). Induction of COL2A1, COL10A1, ALP and COX-2 mRNA expression was determined at day $0,4,7$ and 10 by RTqPCR. Sample size is 9 for every time point. (D) Protein samples from 0 and $30 \mathrm{ng} / \mathrm{mL} \mathrm{BMP-2} \mathrm{conditions} \mathrm{(day} \mathrm{14)}$ were analysed for COL2A1, COL10A1, COX-2, RUNX2 and GAPDH by immunoblotting. (E) ATDC5 cells were differentiated in the presence of increasing BMP-2 concentrations and induction of COX-1 and COX-2 mRNAs at day 14 was determined by RT-qPCR. Sample size is 9 for every BMP-2 concentration. (F) Spatiotemporal expression of COX-2, COL10A1 and ALP in 6 weeks old mouse growth plates was determined by IHC. Left upper panel: anti-COX-2, left lower panel: IgG1-control; middle upper panel: anti-COL10A1, middle lower panel: non-immune serum (NIS) control; right upper panel: anti-ALP, right lower panel: IgG control. $\mathrm{PZ}=$ proliferative zone, $\mathrm{HZ}=$ hypertrophic zone. Scale bars indicate $25 \mu \mathrm{m}$. * indicates $p<0.05$.

\section{Results}

\section{BMP-2 increases COX-2 expression during endochondral ossification}

COX-2 expression was determined in the ATDC5 model. ATDC5 differentiation follows a well-defined endochondral program from undifferentiated chondroprogenitor to hypertrophic chondrocyte. Differentiation was initiated as described previously (Atsumi et al., 1990) and was evident after $7 \mathrm{~d}$ of differentiation as measured by Collagen type II (COL2A1) mRNA expression. COL2A1 expression stabilised $10 \mathrm{~d}$ after induction of differentiation (Figure 1A). Hypertrophic differentiation is characterised by upregulation of COL10A 1 mRNA from $10 \mathrm{~d}$ in differentiation (Fig. 1A) and increased further at $14 \mathrm{~d}$ and later time points (see also below; Fig. 5). As an additional hypertrophic marker, increased expression of ALP mRNA was confirmed (Fig. 1A). Similarly, increased mRNA expression was observed over time for other hypertrophic markers as RUNX2, MEF2C, MMP13 and VEGF-a (see below; Fig. 5). COL2A1 and COL10A1 protein expression followed similar expression patterns as their respective mRNAs (Fig. 1B). COX-2 mRNA expression was almost 4-fold upregulated at $14 \mathrm{~d}$ in differentiation (Fig. 1A) and immunoblotting showed that $\mathrm{COX}-2$ protein is expressed during chondrogenesis from day 7 onward (Fig. 1B). We next determined whether in chondroprogenitor cells COX-2 expression is regulated by BMP-2. In a BMP-2 


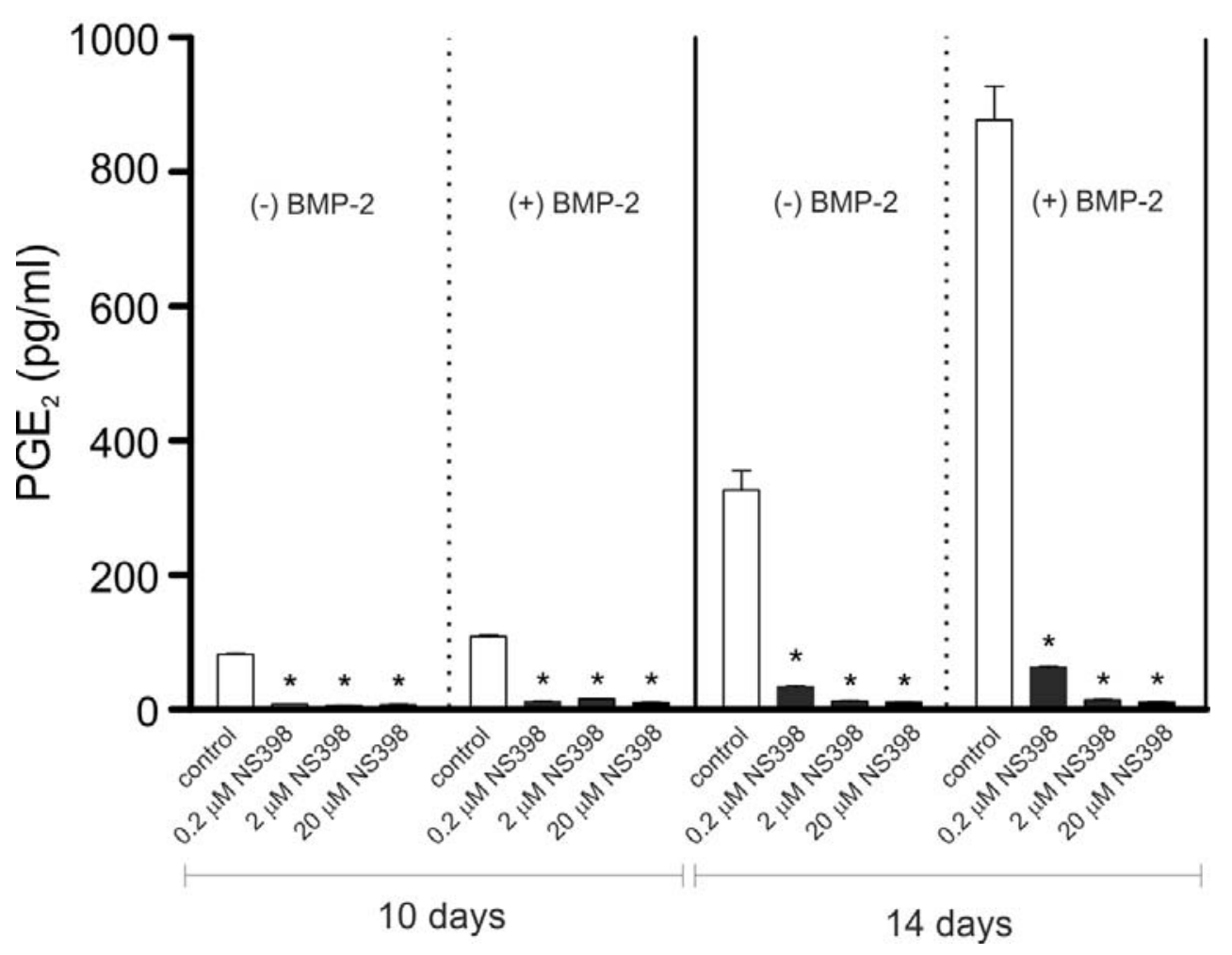

Fig. 2. Inhibition of COX-2 activity during ATDC5 differentiation. ATDC5 cells were differentiated in the absence or presence of $30 \mathrm{ng} / \mathrm{mL}$ BMP-2 and with increasing amounts of NS398 (black bars). COX-2 activity at day 10 and 14 was determined by measuring PGE $_{2}$ synthesis $(\mathrm{pg} / \mathrm{mL})$ using an EIA. Absolute values are shown. Bars represent the mean $\mathrm{PGE}_{2}$-values of independent triplicate samples of 3 individual experiments ( 9 independent supernatant samples) and error bars represent mean \pm s.d.. * indicates $p<0.05$.

dose-response experiment COX-2 mRNA expression responded significantly to a concentration of $30 \mathrm{ng} / \mathrm{mL}$ BMP-2 and was accompanied by a significantly increased COL10A1 and ALP mRNA expression (Fig. 1C). Although COL2A1 mRNA expression was only marginally affected, $30 \mathrm{ng} / \mathrm{mL}$ BMP-2 did result in higher COL2A1 protein expression, as well as increased expression of RUNX2 and COL10A1 $14 \mathrm{~d}$ in differentiation (Fig. 1D). Also COX-2 protein expression responded positively to this BMP-2 condition (Fig. 1D). BMP-2 specifically provoked COX2 expression, as COX-1 expression remained unaltered under various BMP-2 concentrations (Fig. 1E). To further corroborate the relation between COX-2 and chondrocyte hypertrophic differentiation, spatio-temporal expression of COX-2 was determined in the murine growth plate. COX2 is specifically expressed in hypertrophic chondrocytes that express COL10A1 and ALP (Fig. 1F). Throughout hypertrophic differentiation (i.e., more distal to the proliferative zone), expression of COX-2 increased. These data demonstrate that expression of COX-2 correlates with chondrocyte hypertrophic differentiation and suggest that BMP-2 plays a central role in this process.

\section{COX-2 activity is required for chondrocyte hypertrophic differentiation}

To examine COX-2 activity in the context of chondrocyte hypertrophic differentiation, we analysed enzymatic activity of COX-2 by measuring $\mathrm{PGE}_{2}$ levels in culture supernatants. $\mathrm{PGE}_{2}$ was readily detectable at 10 days in differentiation and further increased at $14 \mathrm{~d}$ (Fig. 2; white bars; (-) BMP-2), in good agreement with increased COX-2 expression (Figure 1A/B). In line with the observed BMP2 responsiveness of COX-2 expression (Figure 1C-E), increased $\mathrm{PGE}_{2}$ synthesis in the presence of $30 \mathrm{ng} / \mathrm{mL}$ BMP-2 (Fig. 2; white bars; (+) BMP-2) indicated enhanced levels of enzymatically active COX-2. To substantiate a functional link between COX-2 protein levels and prostaglandin synthesis, we pharmacologically inhibited COX-2 enzyme activity using NS398. Specificity of NS398 for COX-2 over COX-1 was confirmed (Fig. 3). Addition of NS398 almost completely abolished $\mathrm{PGE}_{2}$ synthesis to near-background levels (Fig. 2; black bars), confirming a role for COX-2-mediated prostaglandin synthesis during chondrogenic differentiation.

Next, we analysed whether COX-2 inhibition influences chondrogenic differentiation in the absence or presence of exogenous BMP-2. Differentiation medium was supplemented with increasing NS398 concentrations and chondrogenic marker expression was analysed at 14 $\mathrm{d}$ into differentiation. In the absence of BMP-2, $20 \mu \mathrm{M}$ NS398 reduced COL10A1 protein and mRNA expression (Fig. 4A/B). In line with reduced COL10A1 expression, RUNX2 protein expression was reduced by $20 \mu \mathrm{M}$ NS398 (Fig. 4A), whereas under all NS398 conditions COL2A1 


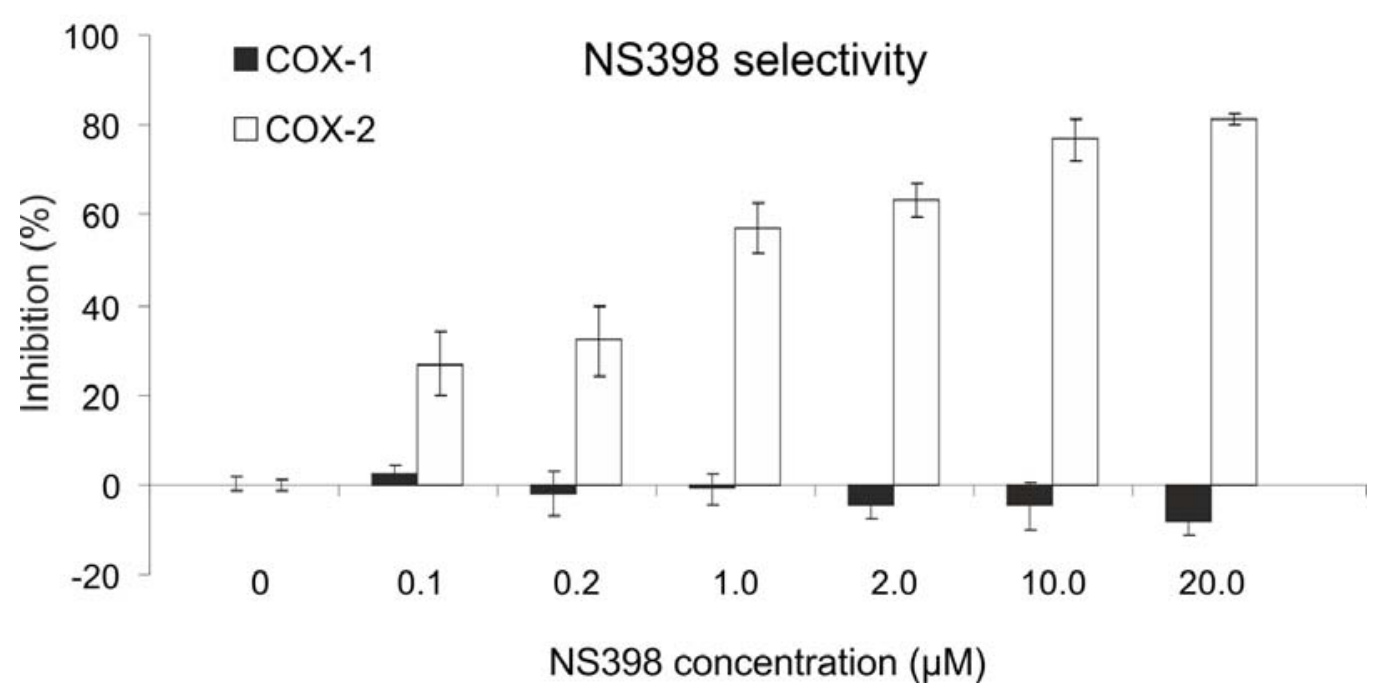

Fig. 3. Selectivity of NS398 for COX-2. The selectivity of NS398 for COX-2 over COX-1 was determined using a COX-1/COX-2 colorimetric inhibition assay. NS398 was tested at 0, 0.1, 0.2, 1.0, 2.0, 10.0 and 20.0 $\mu \mathrm{M}$. The inhibitory capacity was determined as "percent inhibition" compared to a maximum activity control condition. Bars represent average inhibition percentages of COX-1 (black bars) and COX-2 (white bars). Measurements were done in triplicate and error bars represent the variances in inhibitory activity.

protein and mRNA levels remained unaltered (Fig. 4A/B). In the presence of exogenous BMP-2 $(30 \mathrm{ng} / \mathrm{mL})$, overall COL2A1, COL10A1, ALP and RUNX2 levels were increased, confirming its pro-chondrogenic action (Fig. 4A/B). The exposure to BMP-2 evoked an increased NS398 responsiveness, as COL10A1, ALP and RUNX2 expression are more efficiently downregulated by NS398 as compared to the condition without BMP-2 (Fig. 4A/B), whereas COL2A1 protein and mRNA expression remained unchanged with increasing NS398 concentrations under BMP-2 conditions (Fig. 4A/B). Reduced endogenous BMP-2 mRNA levels under BMP-2 supplemented conditions point to a negative auto-feedback mechanism (Fig. 4C). In addition, the sharp NS398 dose-dependent decline of BMP-2 mRNA levels suggests a crucial COX-2 activity-dependent positive effect on endogenous BMP2 regulation (Fig. 4C). The negative effect of COX-2 inhibition on chondrocyte hypertrophic differentiation was further established by measuring ALP enzymatic activity (Fig. 4D). Following ATDC5 differentiation, ALP activity increased and consistent with above findings the presence of $30 \mathrm{ng} / \mathrm{mL}$ BMP-2 evoked significantly higher ALP activity at 7 and 14 days in differentiation. In agreement with the anti-hypertrophic action of COX-2 inhibition, ALP activity was significantly decreased in NS398 conditions. Consistent with a positive feedback mechanism, BMP2 supplementation increased COX-2 expression (Fig. 1C-E, and 4C). Canonical Wnt- and SMAD-signalling are important regulators of chondrocyte hypertrophic differentiation (Dong et al., 2006; Hellingman et al., 2011). Involvement of these two pathways in the COX-2 mediated hypertrophic differentiation was determined by immunoblotting (Fig. 4E). In keeping with involvement in chondrocyte hypertrophy, the level of active phospho-
SMAD1/5/8 increased in the BMP-2 condition (Fig. 4E; lanes 1 vs. 3). However, inhibition of COX-2 activity by NS398 did not influence the phosphorylation level of SMAD1/5/8 (Fig. 4E; lanes 1 vs. 2 and 3 vs. 4). Canonical Wnt-signalling transcriptionally regulates RUNX2 levels via $\beta$-catenin. Whereas BMP-2 only marginally enhanced $\beta$-catenin levels (Fig. 4E, short exposure; lanes 1 vs. 3), inhibition of COX-2 activity caused a sharp decline in $\beta$-catenin levels in both the absence as well as the presence of BMP-2 (Fig. 4E; lane 1 vs. 2 and 3 vs. 4), consistent with a possible regulatory role for $\mathrm{COX}-2$ activity in chondrocyte hypertrophy via $\mathrm{Wnt} / \beta$-catenin-signalling.

In the data presented above, COX-2 was inhibited from the onset of differentiation $(\mathrm{t}=0)$ onward. However, COX-2 protein expression during ATDC5 differentiation is first detectable at day 7 onward (Fig. 1B). To determine a possible window of action, we therefore asked whether inhibition of COX-2 at later differentiation stages would show the inhibitory effect on chondrocyte hypertrophy. Differentiation medium was supplemented with $20 \mu \mathrm{M}$ NS398 from day 7 onward and chondrogenic differentiation was monitored until day 21. Analyses of hypertrophic marker expression (COL10A1, RUNX2, MEF2C, MMP13, VEGF-a and ALP) revealed that inhibition of COX-2 caused significantly lower upregulation of all markers at 14 and or 21 days in differentiation (Fig. 5). Of note, NS398 did not significantly influence COL2A1 mRNA expression at day 14 , whereas it caused a significantly higher upregulation further in differentiation (day 21). Combined, these results clearly show that inhibition of COX-2 activity specifically affects late, hypertrophic chondrocyte differentiation, independently of early chondrogenic commitment. 
A

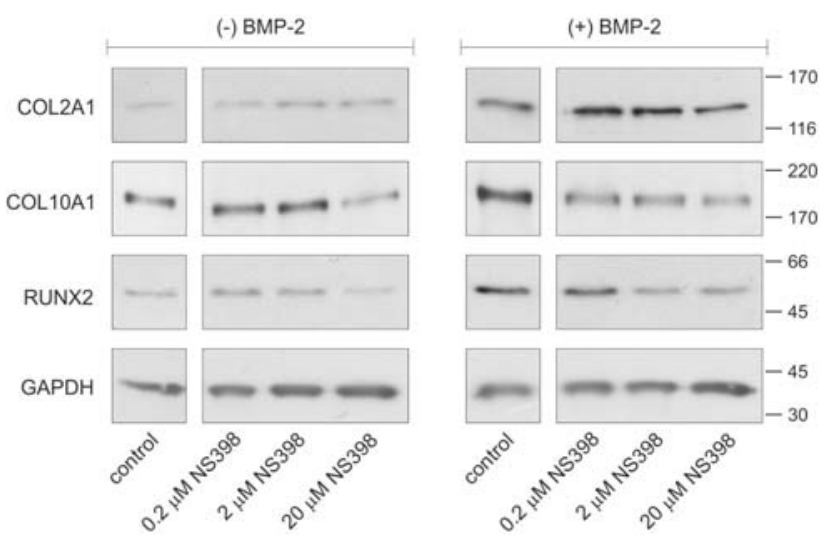

B

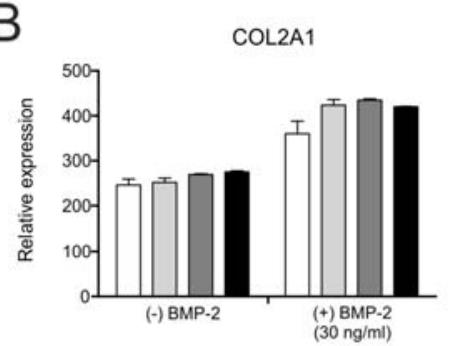

C

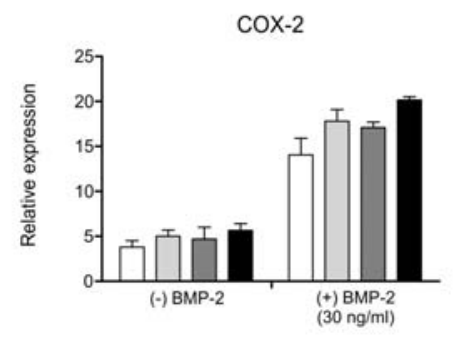

D
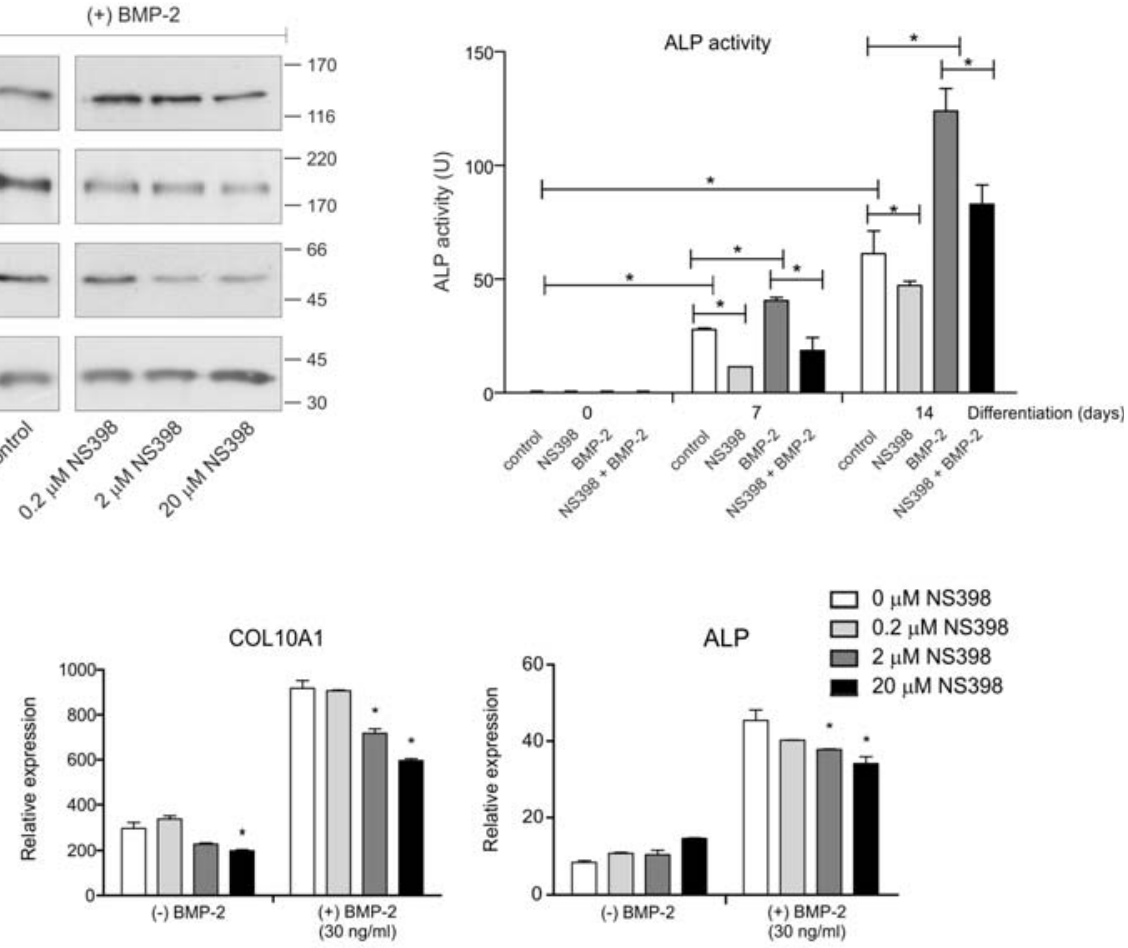

E

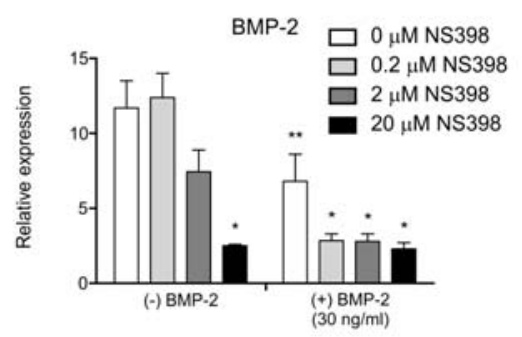

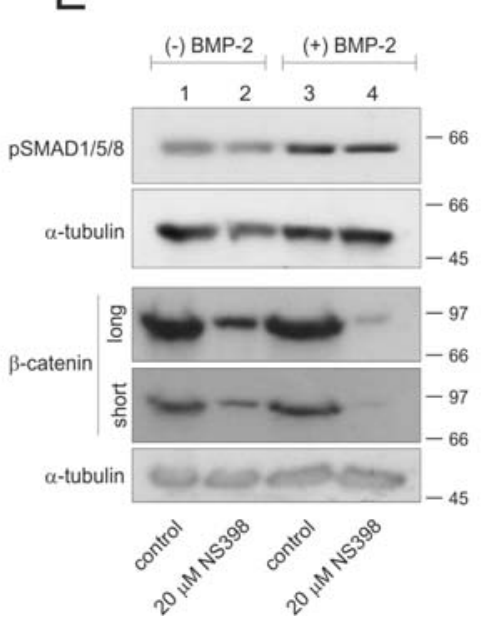

Fig. 4. Inhibition of COX-2 activity decreases chondrocyte hypertrophic differentiation.

(A) Increasing NS398 concentrations were added to differentiating ATDC5 cultures in the absence (left panel set) or presence of $30 \mathrm{ng} / \mathrm{mL}$ BMP-2 (right panel set). Protein expression of COL2A1, COL10A1 and RUNX2 was analysed in day 14 cell extracts. (B) Induction of COL2A1, COL10A1 and ALP mRNA expression in day 14 samples from same experiment as (A) was determined. White bars: control, grey and black bars: NS398 conditions. Nine samples per condition were measured. (C) COX-2 and BMP-2 mRNA induction was determined in similar samples as (B). In addition to shown statistical analyses, for BMP-2 mRNA the statistical significance was also determined between the (-) BMP-2 and (+) BMP-2 condition without NS398 (** indicates $p<0.05$ ). Sample size is equal to (B). (D) ATDC5 cells were differentiated for 7 or 14 days in the absence pr presence of BMP-2 (30 ng/mL) or NS398 (20 $\mu \mathrm{M})$ and combinations thereof. ALP enzymatic activity $(\mathrm{U})$ of triplicate samples was determined and normalised to total protein content. (E) In cell extracts from (A), levels of p-SMAD1/5/8 (upper panel set) and $\beta$-catenin (lower panel set; long and short refer to different ECL exposure times) were determined. * indicates $p<0.05$. 
COL2A1

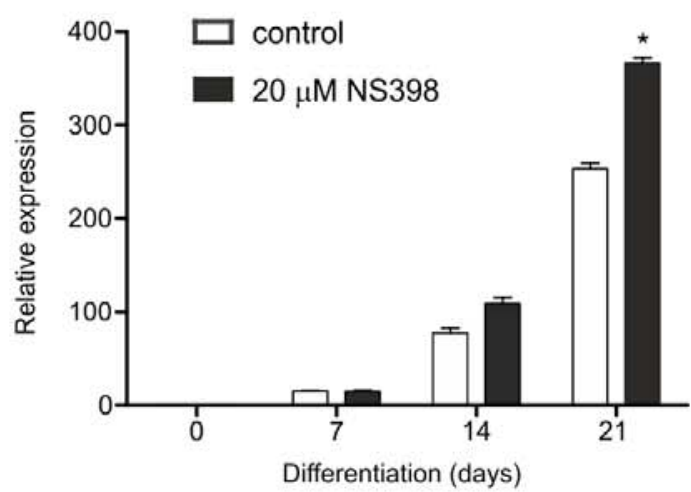

MEF2C

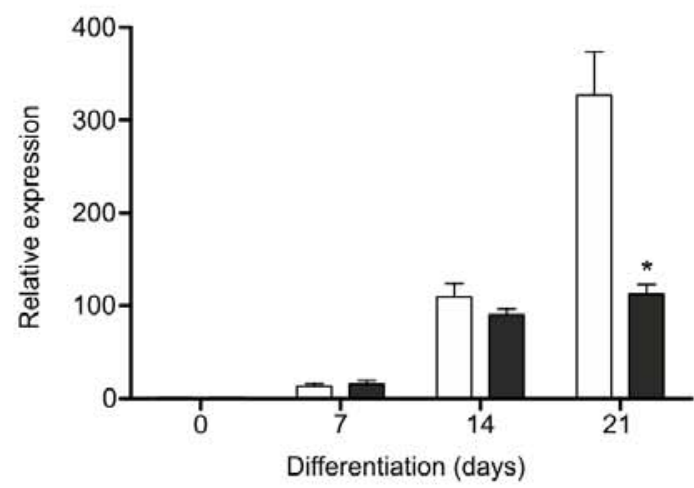

MMP13

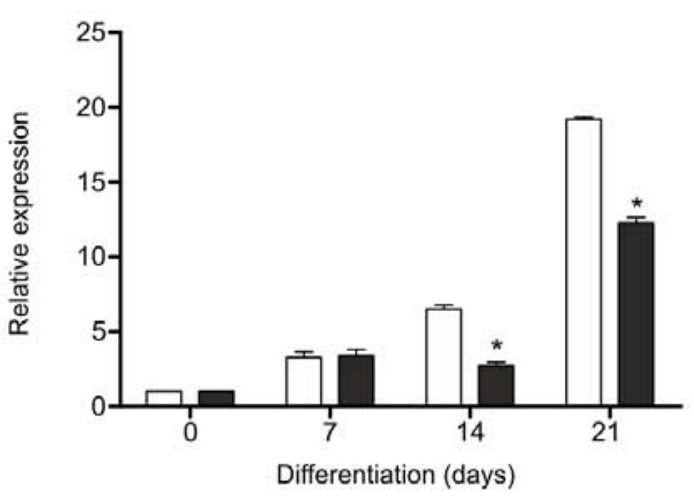

ALP

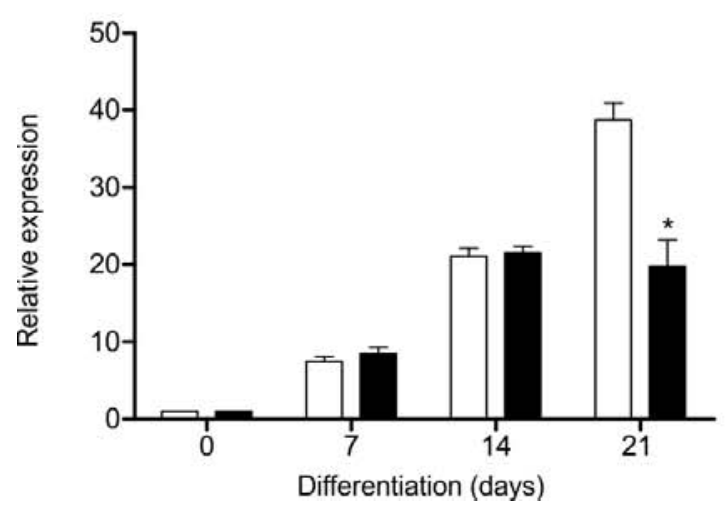

COL10A1

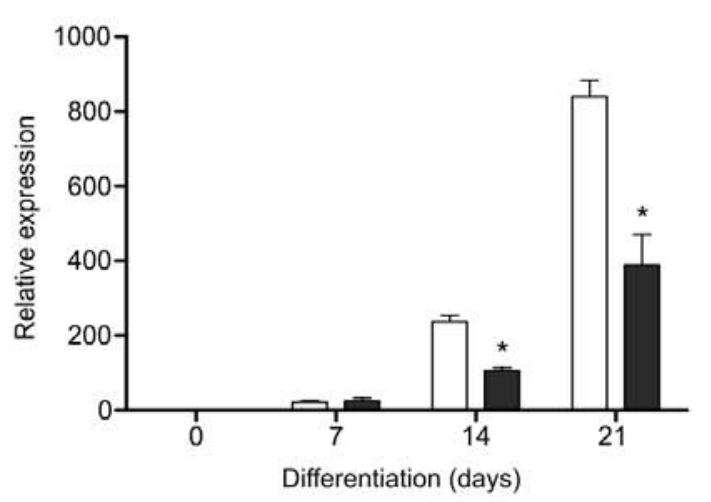

RUNX2

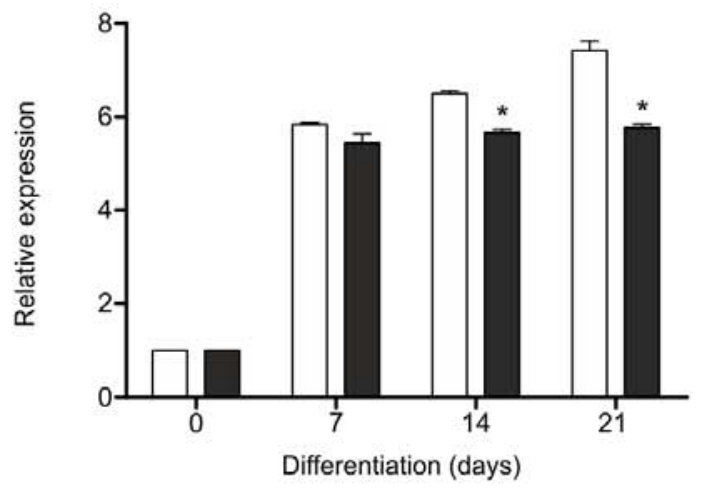

VEGF-a

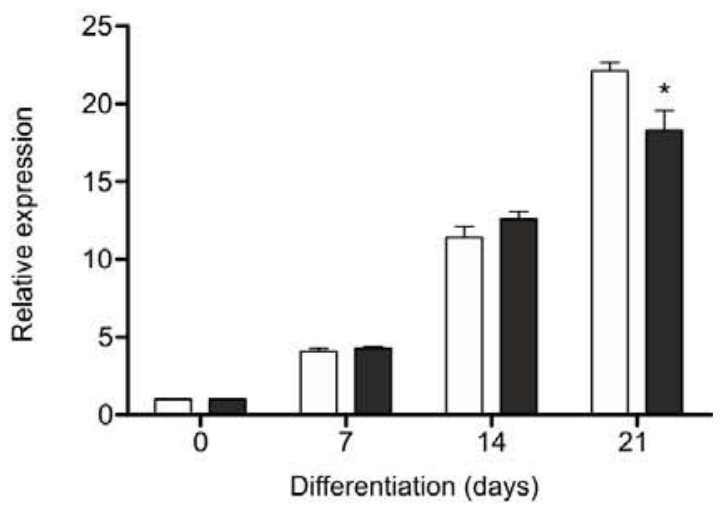

Fig. 5. Inhibition of COX-2 activity decreases chondrocyte hypertrophic differentiation independent of the differentiation phase. ATDC5 cultures were differentiated for 7 days. After 7 days COX-2 activity was continuously inhibited by addition of NS398 until day 21 into differentiation. In day 0 , 7, 14 and 21 samples, gene expression of COL2A1, COL10A1, RUNX2, MEF2C, MMP13, VEGF-a and ALP was determined. For every condition and time point 8 individual samples were measured. White bars indicate the control (DMSO) and black bars represent the $20 \mu \mathrm{M}$ NS398 condition. * indicates $p<0.05$. 

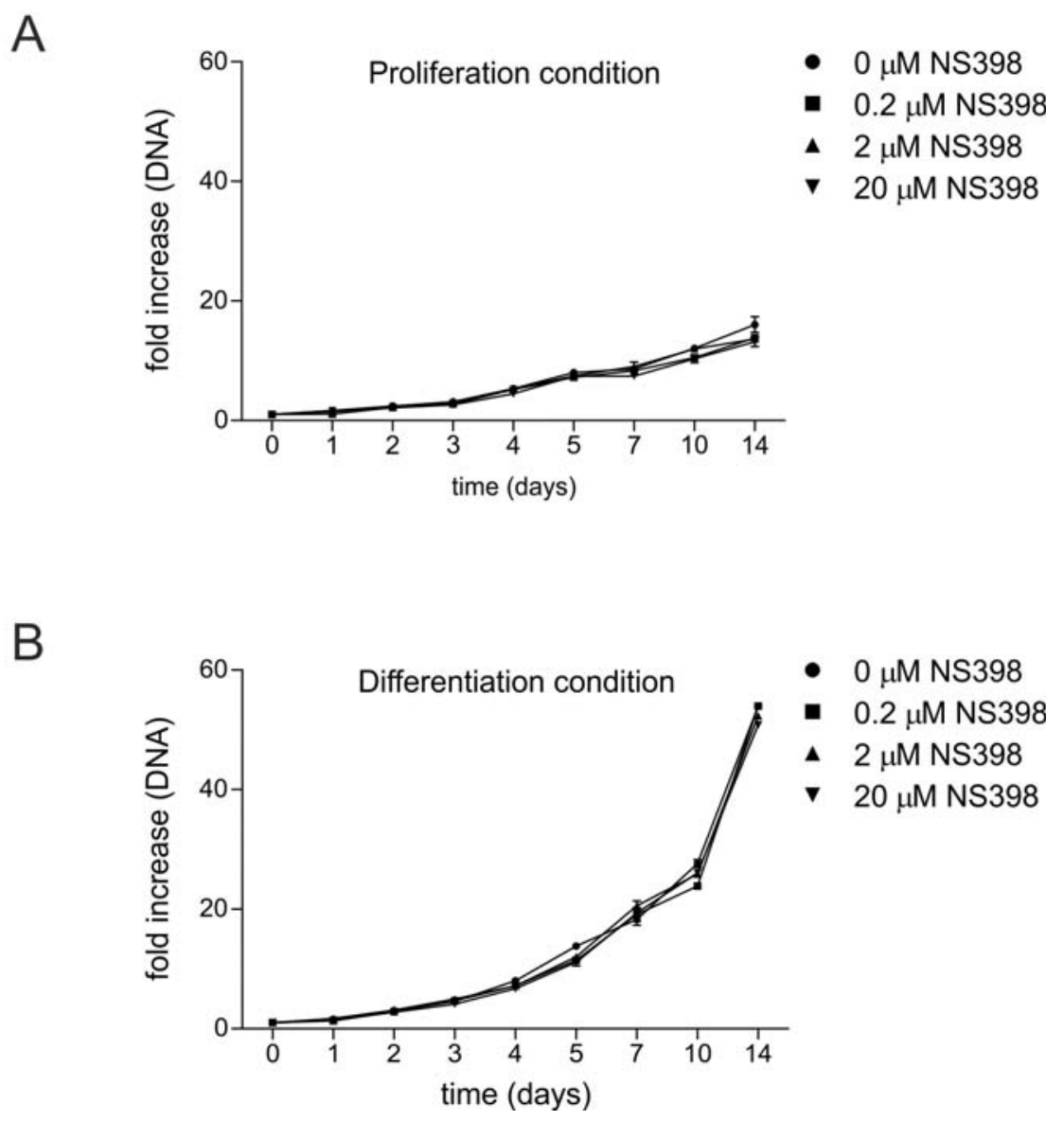

Fig. 6. Influence of COX-2 inhibition on ATDC5 proliferation rate. Proliferation speed of ATDC5 cells was determined under either proliferation (A) or differentiation (B) conditions and in the presence of increasing concentrations of NS398. X-violet staining was conducted collectively on fixated day $0,1,2,3,4,5,7,10$ and 14 samples and absorbance of the eluates was determined spectrophotometrically. Fold increase (DNA) from samples was calculated relatively to day 0 . The data points represent the average of 6 independent samples and error bars represent mean \pm s.d..

\section{Inhibition of COX-2 activity does not affect chondrocyte cell proliferation}

As proliferation is a crucial aspect of ATDC 5 chondrogenic differentiation (Atsumi et al., 1990), we addressed a potential effect of COX-2 inhibition on cell proliferation under proliferation and chondrogenic conditions. To this end, we generated growth curves with increasing NS398 concentrations $(0,0.2,2$ and $20 \mu \mathrm{M})$. Under proliferation conditions, cell numbers increased approximately 15 fold over a $14 \mathrm{~d}$ time span (Fig. 6A). None of the NS398 concentrations affected cell proliferation. Under chondrogenic conditions, cellular proliferation rate is significantly increased over normal proliferation conditions (Fig. 6B). Again, NS398 did not affect cell proliferation rate at any of the tested concentrations under differentiation conditions. Overall, these data show that specific inhibition of COX-2 activity during ATDC5 proliferation and chondrogenic differentiation does not affect the proliferative capacity of ATDC5 and thus excludes an effect of NS398 on hypertrophic differentiation through impaired proliferation capacity.

\section{Inhibition of chondrocyte hypertrophic differentiation in PAC}

To verify the anti-hypertrophic effect of COX-2 inhibition in vitro, we adopted an ex vivo periosteal organ culture system suitable to display chondrogenic potential (O'Driscoll et al., 1994). Importantly, the use of periosteal tissue is directly relevant for endochondral ossification processes (Dwek, 2010). The mesenchymal progenitor cell-containing tissue is cultured in between agarose layers (periosteum agarose culture: PAC), and induced to differentiate by TGF $\beta 3$. Chondrogenic differentiation of PACs was evident after 20 $\mathrm{d}$, as visualised by safranin-O staining of tissue sections. Increasing intensity of safranin-O staining after 40 culturedays indicates increased proteoglycan deposition (Fig. 7A). TGF $\beta$ is absolutely required for the PAC model, as in its absence mature chondrocytes are not formed and cartilage matrix deposition is not detectable at $20 \mathrm{~d}$ ((O'Driscoll et al., 1994) and Fig. 7B; left panel). In agreement with a prominent role for BMP-2 in chondrocyte hypertrophy, combined treatment with TGF $\beta 3$ and BMP-2 clearly resulted in a hypertrophic PAC morphology at $20 \mathrm{~d}$ (Fig. $7 \mathrm{~B}$; right panel) as compared to single treatment with 
A

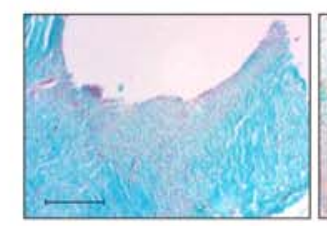

0 days (fresh periosteum)

B

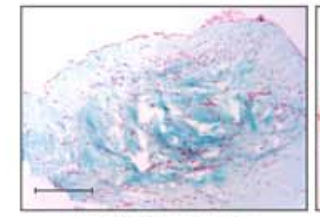

(-) TGFB3 (-) BMP-2

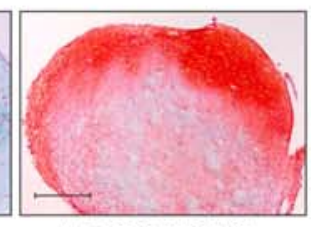

(+) TGF $\beta 3$ (-) BMP-2

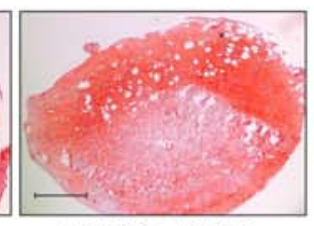

(+) TGFB3 (+) BMP-2
D

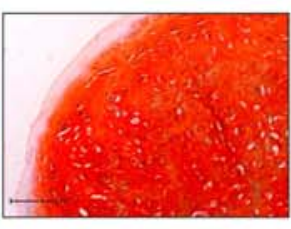

40 days

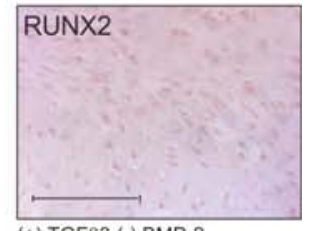

(+) TGFB3 (-) BMP-2

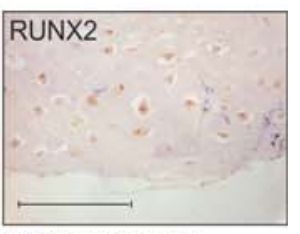

(+) TGFB3 (+) BMP-2
C
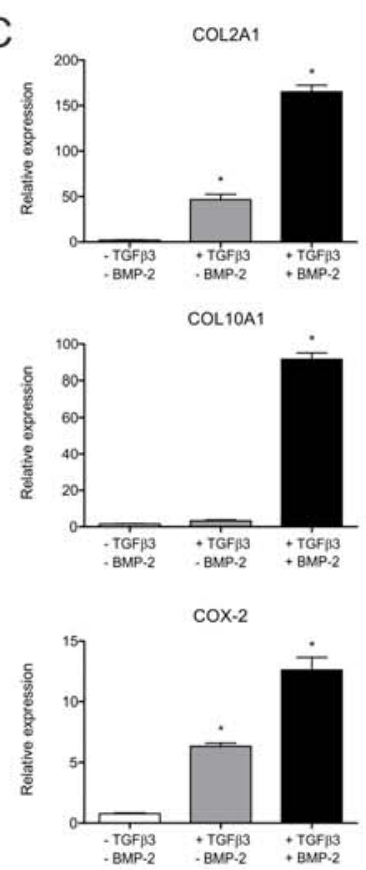

$\mathrm{F}$

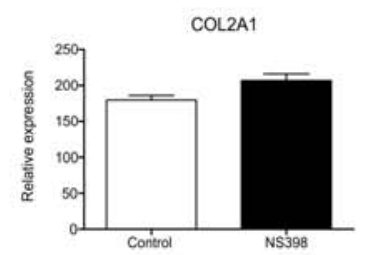

COL10A1

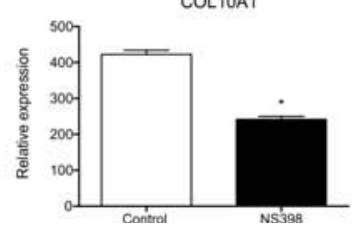

$E$
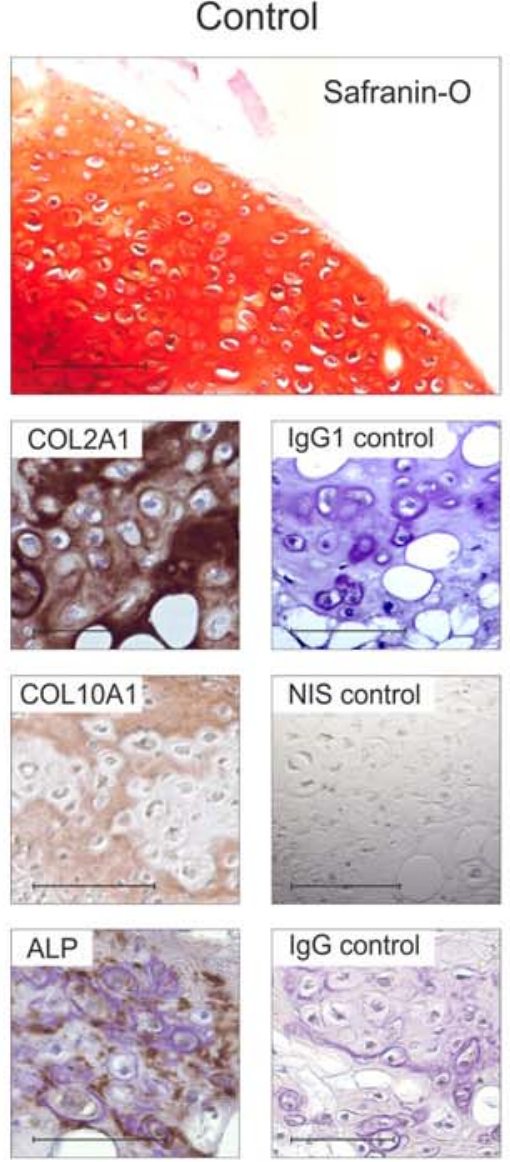

G

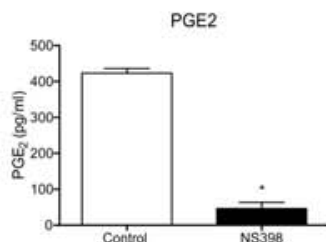

NS398
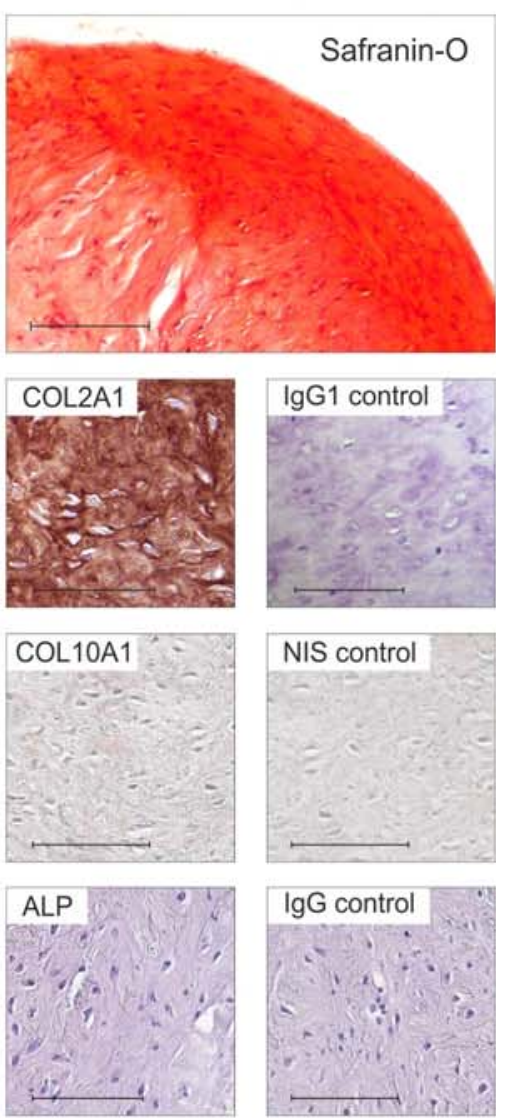

Fig. 7. BMP-2 mediated chondrocyte hypertrophy in PAC is decreased by COX-2 inhibition. (A) Periosteum agarose cultures (PACs) were differentiated for $0,10,20$ or 40 days as previously described previously (O'Driscoll et al., 1994). Five $\mu \mathrm{m}$ sections were stained with Safranin-O/Fast green (bars represent $100 \mu \mathrm{m}$ ). (B) PACs were differentiated in the absence of TGF $\beta 3$, in the presence of TGF $\beta 3(10 \mathrm{ng} / \mathrm{mL})$ or in the presence of TGF $\beta 3(10 \mathrm{ng} /$ $\mathrm{mL})$ and BMP-2 $(30 \mathrm{ng} / \mathrm{mL})$. The panel shows representative examples of PAC tissue sections $(20 \mathrm{~d})$ stained with 
...Fig. 7. (continued)

Safranin-O/Fast (bars represent $1 \mathrm{~mm}$ ). (C) Conditions mentioned in (B) were also analysed quantitatively by RTqPCR for induction of COL2A1, COL10A1 and COX2 mRNA expression. Bars represent the average of 6 individual PAC samples and error bars represent mean \pm s.d. (D) Hypertrophic differentiation of these samples was assessed by immunohistochemical staining of RUNX2 (bars represent $100 \mu \mathrm{m})$. (E) PACs were differentiated (20 d) in the presence of TGF $\beta 3$ and BMP-2 with or without supplementation of NS398 $(2 \mu \mathrm{M})$. Tissue sections $(5 \mu \mathrm{m})$ were stained with Safranin-O/Fast green (top micrographs). Immunohistochemical stainings were performed to visualise COL2A1 (upper micrographs), COL10A1 (middle micrographs) and ALP (lower micrographs) (bars represent 100 $\mu \mathrm{m})$. Negative controls are depicted for each immuno staining: negative IgG1 control for COL2A1; non-immune rabbit serum (NIS) for COL10A1 and non-immune goat IgGs for ALP. (F) PACs were differentiated in conditions as used in (E) and induction of COL2A1 and COL10A1 expression was determined. Bars represent the average of 6 individual PAC samples and error bars indicate mean \pm s.d. (G) Inhibition of COX-2 activity was confirmed in samples from $(\mathrm{F})$ by measuring $\mathrm{PGE}_{2}$ synthesis $(\mathrm{pg} / \mathrm{mL})$. Absolute values are shown. * indicates $p<0.05$.

A

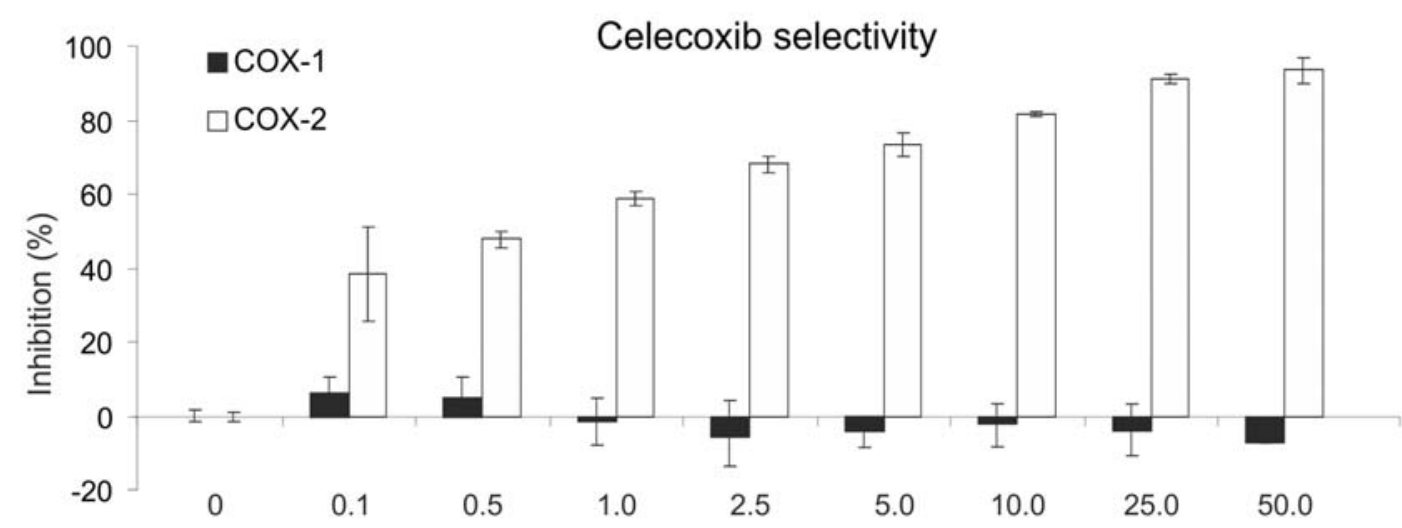

Celecoxib concentration $(\mu \mathrm{M})$

B
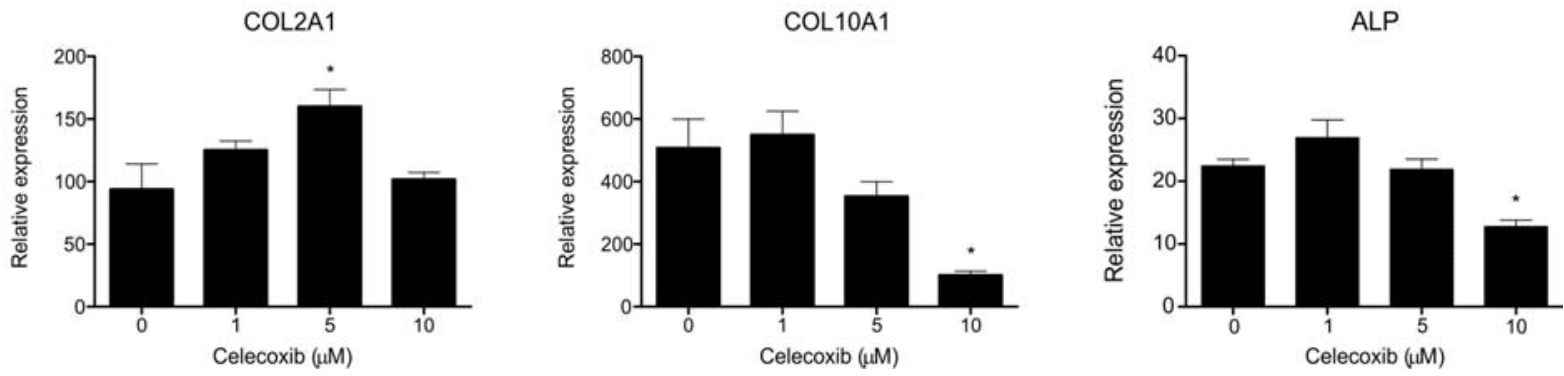

Fig. 8. Celecoxib properties. (A) The selectivity of Celecoxib for COX-2 over COX-1 was determined using a COX-1/COX-2 colorimetric inhibition assay. NS398 was tested at $0,0.1,0.5,1.0,2.5,5.0,10.0,25.0$ and $50.0 \mu \mathrm{M}$. The inhibitory capacity was determined as "percent inhibition" compared to a maximum activity control condition. Bars represent average inhibition percentages of COX-1 (black bars) and COX-2 (white bars). Measurements were done in triplicate and error bars represent the variances in inhibitory activity. (B) Increasing concentrations of Celecoxib were added to differentiating ATDC5 cultures. Messenger RNA expression of COL2A1, COL10A1 and ALP in day 14 samples was determined. Bars represent the average of 3 independent samples and error bars represent mean \pm s.d.. Significances were calculated using Student's $t$-test. * indicates $p<0.05$.

TGFß3 (Fig. 7B; middle panel) or BMP-2 alone (data not shown). Gene expression analyses confirmed that chondrocyte hypertrophy in the PAC system completely dependents on BMP-2: COL10A1 mRNA(Fig. 7C; middle panel) and RUNX2 protein (Fig. 7D) are only induced when TGF $\beta 3$ is combined with BMP-2. Consistent with its requirement for chondrogenesis, TGF $\beta 3$-only treated PACs show moderate COL2A1 mRNA induction, which is more than 3-fold enhanced by combination treatment with BMP-2 (Fig. 7C; upper panel). 
A

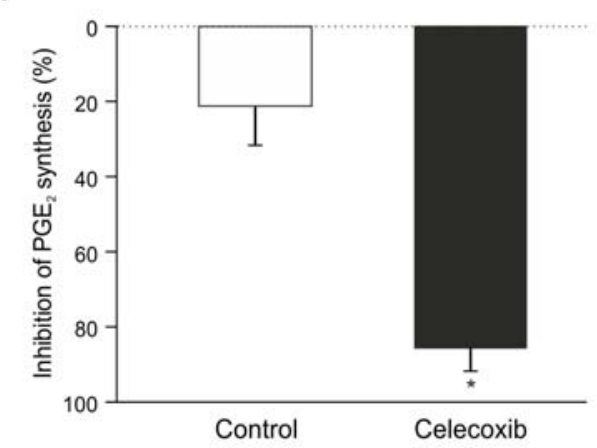

B

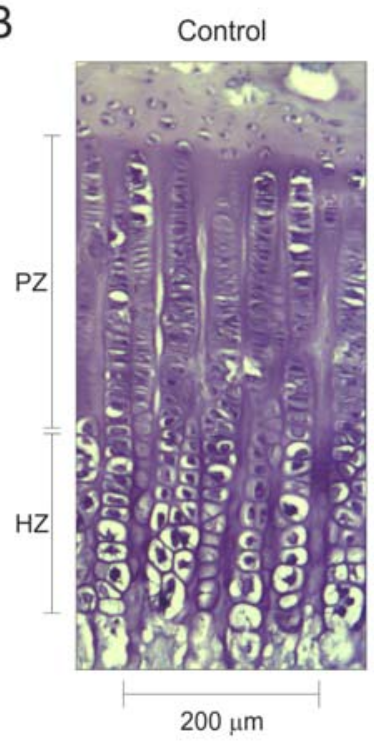

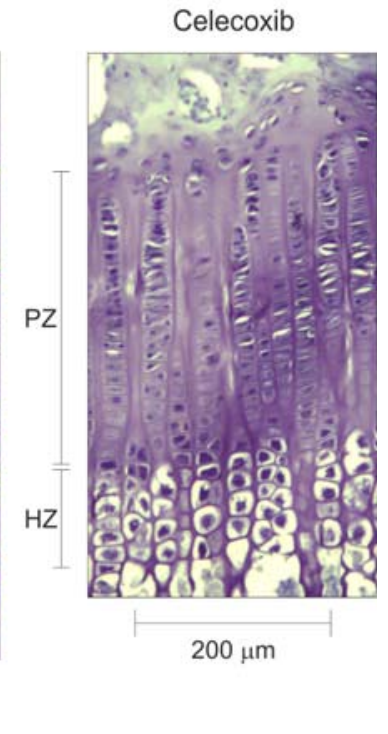

C

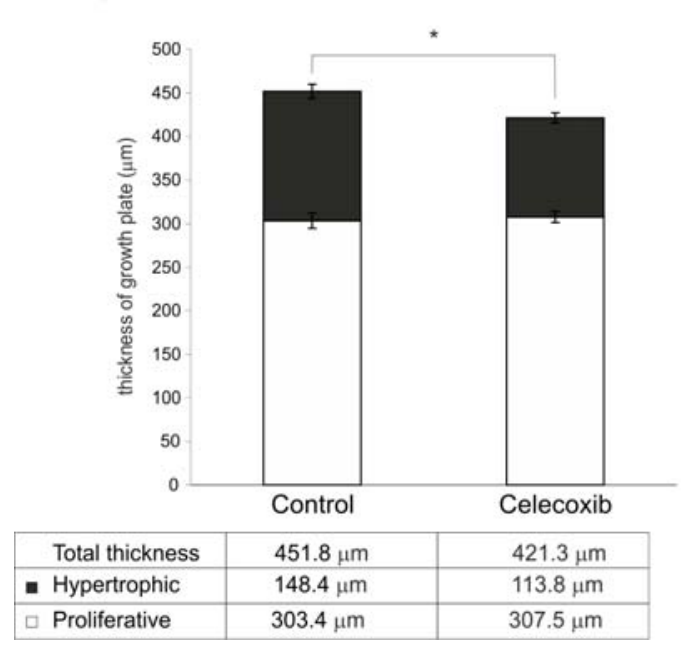

D

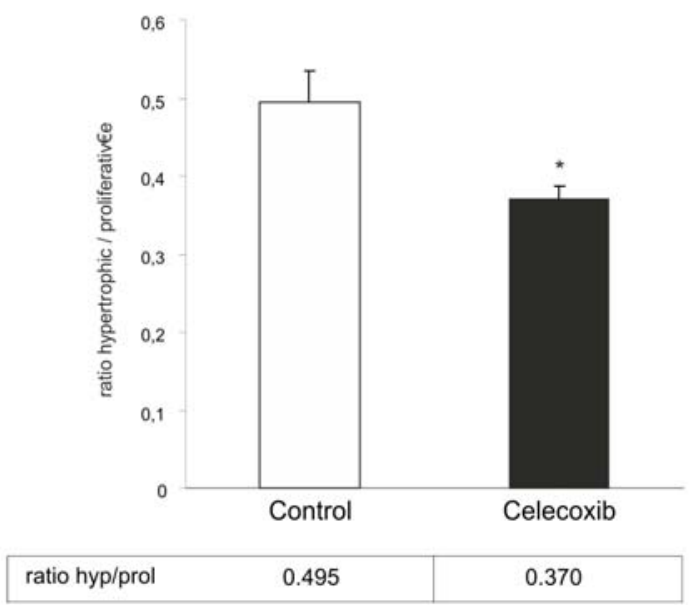

Fig. 9. Chondrocyte hypertrophic differentiation in the rabbit growth plate is impaired by inhibition of COX2 activity. Skeletally immature New Zealand white rabbits received Celecoxib (7 animals) on a daily basis. Six control animals were used. Rabbits were treated for 3 weeks. (A) COX-2 inhibition was confirmed by measuring $\mathrm{PGE}_{2}$ levels in serum at 3 weeks. Inhibition of $\mathrm{PGE}_{2}$ synthesis was determined as $\%$ decrease as compared to pretreatment serum samples. (B) Representative examples of growth plate sections of control and Celecoxib treated rabbits. $\mathrm{PZ}=$ proliferative zone, $\mathrm{HZ}$ = hypertrophic zone. The scale bar represents $200 \mu \mathrm{m}$. (C) Quantification of growth plate zones of both groups. Normal distribution of the data was confirmed by a Shapiro-Wilk test. White bars: proliferative zone, black bars: hypertrophic zones. Average total thickness control group $=451.8 \mu \mathrm{m}$; Celecoxib group $=421.3 \mu \mathrm{m}($ Mann-Whitney, $p=0.032)$. PZ control group $=303.4 \mu \mathrm{m} ; \mathrm{PZ}$ Celecoxib group $=307.5 \mu \mathrm{m}$ (Mann-Whitney, $p=0.668)$. HZ control group $=148.4 \mu \mathrm{m} ; \mathrm{HZ}$ Celecoxib group $=113.8 \mu \mathrm{m}$ (Mann-Whitney, $p$ $=0.046)$. (D) Ratios between the hypertrophic and proliferative zones of the control and Celecoxib groups were determined (Mann-Whitney, $p=0.013$ ). * indicates $p<0.05$.

To analyse the relationship between COX-2 and chondrocyte hypertrophy in PACs, COX-2 gene expression was determined: TGF $\beta 3$ induced COX-2 expression, which is increased almost 2-fold by BMP-2 (Fig. 7C; lower panel), confirming that chondrocyte hypertrophic differentiation also correlates to COX-2 levels in an independent ex vivo model. To further substantiate the requirement of COX-2 activity for hypertrophic differentiation, the effect of NS398 on the PAC model (with
BMP-2 treatment) was evaluated. Two micromolar NS398 did not alter proteoglycan deposition (Fig. 7E, upper right panel) and correspondingly COL2A1 expression was not affected (Fig. 7E, COL2A1 panel sets and Fig. 7F, upper panel), consistent with our in vitro findings. In contrast, NS398 treatment strongly reduced COL10A1 expression (Fig. 7E, COL10A1 panel sets and Figure 7F, lower panel), ALP expression (Fig. 7E, ALP panel sets) and prevented the hypertrophy-associated chondrocyte morphological 


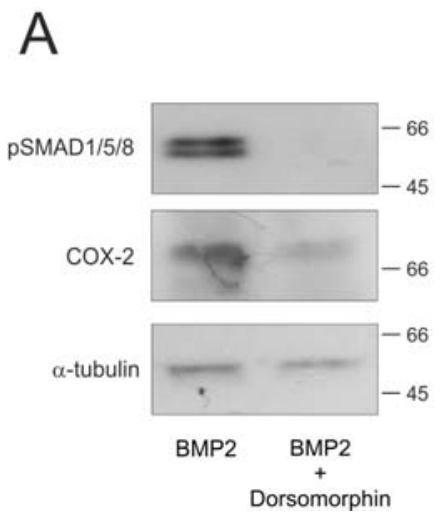

B

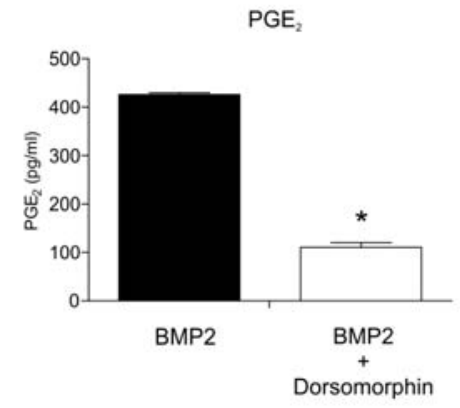

C

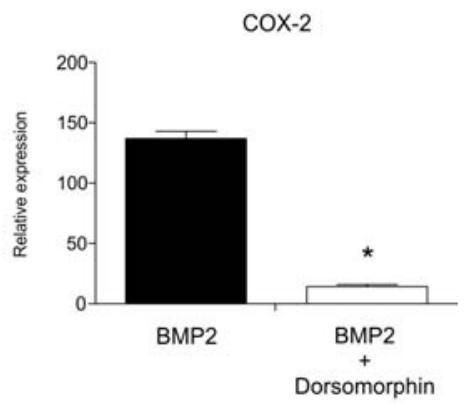

Fig. 10. SMAD1/5/8 activity and COX-2. To determine whether BMP-2 induced SMAD1/5/8 activity regulates COX-2 we employed Dorsomorphin $(10 \mu \mathrm{M})$ on ATDC5 cells in the presence of BMP-2 $(30 \mathrm{ng} / \mathrm{mL})$. (A) Differentiating ATDC5 cells were treated with BMP-2 and BMP-2 + Dorsomorphin for $1 \mathrm{~d}$. Protein extracts were analysed by immunoblotting for phosphorylation (= activation) of SMAD1/5/8 and expression of COX-2. Lack of detection of p-SMAD1/5/8 confirmed Dorsomorphin functionality. Decreased expression of COX-2 accompanied inhibition of SMAD1/5/8 phosphorylation. (B) To confirm decreased total COX-2 activity, PGE 2 levels were determined in culture supernatants. Decreased $\mathrm{PGE}_{2}$ levels confirm the Dorsomorphin-induced COX-2 decrease. Three independent supernatants were measured per condition. (C) To place the above finding in a chondrocyte hypertrophic context, ATDC 5 cells were differentiated for $14 \mathrm{~d}$ in the presence of BMP-2 and Dorsomorphin was added from day 7 on (comparable to (Hellingman et al., 2011)). Confirming above data, Inhibition of SMAD1/5/8 phosphorylation resulted in a significantly lower expression of COX-2 mRNA as compared to the BMP- 2 control.

changes in PACs (Fig. 7E, upper right panel). COX-2 inhibition was confirmed by an almost complete lack of $\mathrm{PGE}_{2}$ synthesis in the NS398 condition (Fig. 7G).

\section{Selective inhibition of COX-2 impairs chondrocyte hypertrophic differentiation in the growth plate}

To further corroborate our findings in a developmentally and pharmacologically relevant in vivo context, we determined whether treatment with a clinically relevant selective COX-2 inhibitor, Celecoxib, affected growth plate development in vivo. Celecoxib selectively inhibited COX-2 over COX-1 (Fig. 8A). A dose-response analysis confirmed a similar anti-hypertrophic action for Celecoxib as for NS398: $10 \mu \mathrm{m}$ Celecoxib significantly decreased COL10A1 and ALP mRNA upregulation at day 14 in ATDC5 differentiation, whereas it showed no negative effect on COL2A1 mRNA expression (Fig. 8B). To determine the consequences of selective COX-2 inhibition on growth plate development, skeletally immature New Zealand white rabbits were systemically treated with Celecoxib for 3 weeks ( 6 animals in control group and 7 animals in Celecoxib group). In blood plasma we confirmed that Celecoxib efficiently inhibited in vivo $\mathrm{PGE}_{2}$ synthesis and thus systemically inhibited COX-2 (Fig. 9A). Growth plate sections of the ulnae were stained with haematoxylin (Fig. 9B). Analysis of the total growth plate thickness of control sections revealed an average thickness of $451.8 \mu \mathrm{m}$ (Fig. 9C). In contrast, the average thickness of the growth plates of the Celecoxib-treated group was significantly reduced to $421.3 \mu \mathrm{m}$ (Fig. 9B/C). To discern a potential effect of Celecoxib on early versus late chondrogenic differentiation stages, the thickness of the proliferative and hypertrophic zones were measured separately. Importantly, and consistent with our in vitro and ex vivo findings, the length of the proliferative zones of both the control and Celecoxib-treated group did not differ significantly (Figure 9B/C). In contrast, the hypertrophic zone of the Celecoxibtreated group was significantly thinner as compared to the control group $(113.8 \mu \mathrm{m}$ vs. $148.4 \mu \mathrm{m}$, respectively; Fig. 9B/C). The ratios of hypertrophic/proliferative zone length of control and Celecoxib treated growth plates were 0.495 and 0.370 , respectively (Fig. 9D). These ratios differ significantly from each other and confirm reduced hypertrophic zone length. The difference in total growth plate thickness thus resulted from impaired development of the hypertrophic zone. Taken together, these in vivo data clearly show that inhibition of COX-2 activity during skeletal development affects growth plate development at the chondrocyte hypertrophic level and provides further evidence in support of a crucial role of COX-2 activity during chondrocyte hypertrophic differentiation in an endochondral ossification context.

\section{Discussion}

The involvement of COX-2 in osteogenic differentiation is well documented in literature. We here also demonstrate a role for COX-2 in the chondrogenic phase of endochondral ossification. Using three independent models we show that late chondrocyte hypertrophy in endochondral ossification is, at least in part, determined by COX-2 activity. We provide evidence that COX-2 function intersects with BMP-2 and $\mathrm{Wnt} / \beta$-catenin signalling. Importantly, the 
finding that the effect of COX-2 inhibition appears restricted to chondrocyte hypertrophic differentiation has important implications for the clinical application of NSAIDs.

\section{COX-2 in chondrocyte hypertrophy}

We demonstrate that COX-2 is expressed in the growth plate, specifically in the prehypertrophic and hypertrophic compartments of the mouse growth plate. Despite apparently discrepant COX-2 staining pattern in the rat growth plate (Brochhausen et al., 2006; Brochhausen et al., 2008), both data sets support a role for COXenzymes in growth plate development. In addition, our in vivo findings demonstrate that systemic COX-2 inhibition during skeletal development results in abnormal development of the hypertrophic zone of the growth plate. These data are consistent with our observations that in in vitro and ex vivo models COX-2 specific NSAIDs decrease chondrocyte hypertrophy. Impaired $\mathrm{Wnt} / \beta$ catenin signalling was shown to cause defective growth plate hypertrophic differentiation (Nagayama et al., 2008) and postnatal cartilage development (Chen et al., 2008). These and our findings predict that the COX-2 -/- mouse (Zhang et al., 2002) should display a, most likely, subtle skeletal developmental phenotype. Although the presence of functionally redundant mechanisms could theoretically explain lack of effects, detailed re-analysis of growth plates in COX-2 -/- mice, may reveal a mild phenotype. Conversely, although we could detect a significant quantitative difference in hypertrophic zone length between Celecoxib and non-treated animals, it remains to be determined whether the effects of transient COX-2 inhibition results in persistent skeletal abnormalities into adulthood.

\section{COX-2 - integration into known chondrogenic signalling}

Hypertrophic chondrocyte differentiation can be monitored by expression of several important markers like RUNX2, COL10A1 and ALP. Direct transcriptional regulation of the COL10A1 gene is regulated by RUNX2 (Zheng et al., 2003) and transcriptional activity of RUNX2 on the COL10A1 promoter is cooperatively controlled by BMP-2-induced SMAD's (Javed et al., 2009). In addition, in osteogenic differentiation phosphorylation has been described as an important determinant for transcriptional activity of RUNX2 (Shui et al., 2003). Chondrocyte hypertrophic differentiation is, at least in part, regulated via SMAD1/5/8 signalling (Hellingman et al., 2011). As we could not detect any difference on SMAD1/5/8 phosphorylation between control and NS398-treated samples, this suggests that COX-2 either acts in parallel to or down-stream of R-SMADs. Indeed we found experimental evidence that support a down-stream relation. Inhibition of SMAD 1/5/8 phosphorylation by Dorsomorphin inhibited COX-2 expression and subsequent $\mathrm{PGE}_{2}$ synthesis (Fig. 10). Concurrent with decreased detection of $\mathrm{PGE}_{2}$ and reduced RUNX2 and COL10A1 levels, BMP-2 mRNA levels are reduced by NS398 in a dose-dependent manner. Hence, the NS398-mediated decrease of COL10A1 expression is consistent with reduced RUNX2 expression. Upstream of RUNX2 we found that $\beta$-catenin levels respond negatively to inhibition of COX-2 activity. Prostaglandin receptors are G-protein coupled receptors that activate PKA and in turn control $\beta$-catenin levels via GSK-3 activity (Fang et al., 2000; Hata and Breyer, 2004). We did not address phosphorylation of RUNX2 in this study. However, taking the previously reported involvement of canonical Wnt-signalling in the transcriptional regulation of RUNX2 expression upon BMP-2 ligand binding into account (Dong et al., 2006), this provides, at least in part, a mechanistic explanation for how inhibition of COX-2 activity reduces $\beta$-catenin levels and leads to reduced chondrocyte hypertrophic maturation.

Combined with data from other groups (Chikazu et al., 2002; Arikawa et al., 2004; Javed et al., 2009; Steinert et al., 2009), our findings strongly support a functional relation between COX-2, $\mathrm{PGE}_{2}$ and BMP-2 in chondrocyte hypertrophy. Chondrocyte hypertrophic differentiation is induced by BMP-2 during chondrogenesis (Steinert et al., 2009). BMP-2 induces COX-2 expression and the increased hypertrophic differentiation by exogenous BMP2 supplementation was diminished by inhibition of COX-2 activity. In addition, endogenous BMP-2 mRNA levels negatively responded to COX-2 inhibition ((Arikawa et al., 2004) and this study), while endogenous BMP-2 mRNA levels were even further decreased in the presence of exogenous BMP-2. Although it remains currently unclear why BMP-2 treatment increases the NS398 responsiveness of hypertrophic markers, it is possible that a negative feedback effect of exogenous BMP-2 on endogenous BMP-2 levels renders hypertrophic differentiation more susceptible to COX-2 inhibition. In contrast to the here reported anti-hypertrophic effect of COX-2 inhibition, $\mathrm{PGE}_{2}$ has been demonstrated to delay (BMP-2 induced) hypertrophic differentiation via PKA and PKC signalling (Li et al., 2004; Clark et al., 2009). These conflicting results may be related to the choice of experimental models: whereas we used chondroprogenitors, PKA/PKC involvement was tested in mature chondrocyte cultures. In relation to this, differentially regulated COX-2 expression during different stages of chondrogenesis was previously suggested (Huh et al., 2003; Ulivi et al., 2008). Importantly, as COX-2 inhibition leads to an indiscriminate shutdown of prostaglandin synthesis, we cannot rule out the possibility that different prostaglandins contribute differently to chondrocyte differentiation.

\section{Clinical use of NSAIDs}

Clinically, NSAIDs are used to block the prostaglandin synthesising enzymes COX-1 and/or COX-2. However, the therapeutic application of NSAIDs in the context of bone fracture healing is currently under debate as COX-inhibition by NSAIDs is reported to delay fracture healing or cause non-union in patients and animal models (Goodman et al., 2002; Gerstenfeld et al., 2003; Thaller et al., 2005; Simon and O'Connor, 2007; Herbenick et al., 2008). COX-2 is reported to be expressed in fracture callus (Zhang et al., 2002; Naik et al., 2009) and molecular genetic mouse models showed that COX-2 and mPGES-1 
activity are critically required for bone fracture union (Zhang et al., 2002; Yamakawa et al., 2008). Although there is increasing evidence in support of a role for COX2 in the chondrogenic phase of endochondral ossification, most studies focused on COX-2 function in the context of the osteogenic phase of endochondral ossification (i.e., osteoblast and osteoclast biology). Here we identified chondrocyte hypertrophy as another important target of COX-2 activity during the process of endochondral ossification. Recent work by Petit and colleagues suggests that expression of COL10A1 mRNA in human bone marrow mesenchymal stem cells is decreased by specific inhibition of COX-1 and 5-LOX (Petit et al., 2010), suggesting similar mechanisms as presented in our present COX-2 study. However, experimental cell models differ between studies and whether or how COX-1 and COX2 work together or fulfil separate roles in hypertrophic differentiation remains to be determined.

In conclusion, we here show that the hypertrophic action of BMP-2 on endochondral differentiating chondrocytes is, at least in part, determined via COX-2 activity. This finding may have multiple clinical implications. Firstly, the negative effects of COX-2 inhibition on growth plate development in skeletally immature animals warrants critical re-evaluation of the clinical context in which NSAIDs and pharmacological equivalents are applied. Secondly, impaired bone fracture healing by NSAIDs may also be explained by impaired chondrogenic differentiation, in addition to the currently known impaired osteogenic differentiation alone.

\section{Acknowledgements}

The authors appreciate the statistical assistance of Dr. I. Punt (Dept. Orthopaedic Surgery, Maastricht University Medical Center, The Netherlands). Dr. M. Rutgers (Dept. Orthopaedic Surgery, University Medical Center Utrecht, The Netherlands) and Dr. M. Tryfonidou (Dept. of Clinical Sciences of Companion Animals, Utrecht University, The Netherlands) for help with immunohistochemistry. The authors also thank Dr. G. Lunstrum (Shriners Hospital for Children, Portland, OR, USA) for providing the antiCollagen type $\mathrm{X}$ serum for immunohistochemistry. This work was financially supported by the Dutch Arthritis Association (grant LLP14) and the Dutch Stichting Annafonds (grants 07/07 and 08/42). Recombinant hBMP2 was a generous gift from Wyeth Pharmaceuticals.

\section{References}

Arikawa T, Omura K, Morita I (2004) Regulation of bone morphogenetic protein-2 expression by endogenous prostaglandin E2 in human mesenchymal stem cells. J Cell Physiol 200: 400-406.

Atsumi T, Miwa Y, Kimata K, Ikawa Y (1990) A chondrogenic cell line derived from a differentiating culture of AT805 teratocarcinoma cells. Cell Differ Dev 30: 109-116.

Brochhausen C, Neuland P, Kirkpatrick CJ, Nusing RM, Klaus G (2006) Cyclooxygenases and prostaglandin
E2 receptors in growth plate chondrocytes in vitro and in situ--prostaglandin E2 dependent proliferation of growth plate chondrocytes. Arthritis Res Ther 8: R78.

Brochhausen C, Zehbe R, Gross U, Libera J, Schubert H, Nusing RM, Klaus G, Kirkpatrick CJ (2008) Cyclooxygenases (COX-1 and COX-2) for tissue engineering of articular cartilage--from a developmental model to first results of tissue and scaffold expression. Biomed Mater Eng 18: 15-23.

Brooks P, Emery P, Evans JF, Fenner H, Hawkey CJ, Patrono C, Smolen J, Breedveld F, Day R, Dougados M, Ehrich EW, Gijon-Banos J, Kvien TK, Van Rijswijk MH, Warner T, Zeidler H (1999) Interpreting the clinical significance of the differential inhibition of cyclooxygenase-1 and cyclooxygenase-2. Rheumatology (Oxford) 38: 779-788.

Chen M, Zhu M, Awad H, Li TF, Sheu TJ, Boyce BF, Chen D, O'Keefe RJ (2008) Inhibition of beta-catenin signaling causes defects in postnatal cartilage development. J Cell Sci 121: 1455-1465.

Chikazu D, Li X, Kawaguchi H, Sakuma Y, Voznesensky OS, Adams DJ, Xu M, Hoshio K, Katavic V, Herschman HR, Raisz LG, Pilbeam CC (2002) Bone morphogenetic protein 2 induces cyclo-oxygenase 2 in osteoblasts via a Cbfal binding site: role in effects of bone morphogenetic protein 2 in vitro and in vivo. J Bone Miner Res 17: 14301440 .

Clark CA, Li TF, Kim KO, Drissi H, Zuscik MJ, Zhang X, O'Keefe RJ (2009) Prostaglandin E2 inhibits BMP signaling and delays chondrocyte maturation. J Orthop Res 27: 785-792.

De Luca F, Barnes KM, Uyeda JA, De-Levi S, Abad V, Palese T, Mericq V, Baron J (2001) Regulation of growth plate chondrogenesis by bone morphogenetic protein-2. Endocrinology 142: 430-436.

Dong YF, Soung do Y, Schwarz EM, O'Keefe RJ, Drissi H (2006) Wnt induction of chondrocyte hypertrophy through the Runx2 transcription factor. J Cell Physiol 208: 77-86.

Dwek JR (2010) The periosteum: what is it, where is it, and what mimics it in its absence? Skeletal Radiol 39: 319-323.

Einhorn TA (2003) Cox-2: Where are we in 2003? - The role of cyclooxygenase- 2 in bone repair. Arthritis Res Ther 5: $5-7$.

Fang X, Yu SX, Lu Y, Bast RC, Jr., Woodgett JR, Mills GB (2000) Phosphorylation and inactivation of glycogen synthase kinase 3 by protein kinase A. Proc Natl Acad Sci U S A 97: 11960-11965.

Gerstenfeld LC, Thiede M, Seibert K, Mielke C, Phippard D, Svagr B, Cullinane D, Einhorn TA (2003) Differential inhibition of fracture healing by non-selective and cyclooxygenase-2 selective non-steroidal antiinflammatory drugs. J Orthop Res 21: 670-675.

Goodman S, Ma T, Trindade M, Ikenoue T, Matsuura I, Wong N, Fox N, Genovese M, Regula D, Smith RL (2002) COX-2 selective NSAID decreases bone ingrowth in vivo. J Orthop Res 20: 1164-1169.

Grohs JG, Schmidt M, Wanivenhaus A (2007) Selective COX-2 inhibitor versus indomethacin for the prevention of heterotopic ossification after hip replacement: a double- 
blind randomized trial of 100 patients with 1-year followup. Acta Orthop 78: 95-98.

Hata AN, Breyer RM (2004) Pharmacology and signaling of prostaglandin receptors: multiple roles in inflammation and immune modulation. Pharmacol Ther 103: $147-166$.

Hellingman CA, Davidson EN, Koevoet W, Vitters EL, van den Berg WB, van Osch GJ, van der Kraan PM (2011) Smad Signaling Determines Chondrogenic Differentiation of Bone-Marrow-Derived Mesenchymal Stem Cells: Inhibition of Smad1/5/8P Prevents Terminal Differentiation and Calcification. Tissue Eng Part A.

Herbenick MA, Sprott D, Stills H, Lawless M (2008) Effects of a cyclooxygenase 2 inhibitor on fracture healing in a rat model. Am J Orthop (Belle Mead NJ) 37: E133-137.

Huh YH, Kim SH, Kim SJ, Chun JS (2003)Differentiation status-dependent regulation of cyclooxygenase-2 expression and prostaglandin E2 production by epidermal growth factor via mitogen-activated protein kinase in articular chondrocytes. J Biol Chem 278: 9691-9697.

Jakob M, Demarteau O, Suetterlin R, Heberer M, Martin I (2004) Chondrogenesis of expanded adult human articular chondrocytes is enhanced by specific prostaglandins. Rheumatology (Oxford) 43: 852-857.

Javed A, Afzal F, Bae JS, Gutierrez S, Zaidi K, Pratap J, van Wijnen AJ, Stein JL, Stein GS, Lian JB (2009) Specific residues of RUNX2 are obligatory for formation of BMP2induced RUNX2-SMAD complex to promote osteoblast differentiation. Cells Tissues Organs 189: 133-137.

Kronenberg HM (2003) Developmental regulation of the growth plate. Nature 423: 332-336.

Li TF, Zuscik MJ, Ionescu AM, Zhang X, Rosier RN, Schwarz EM, Drissi H, O'Keefe RJ (2004) PGE2 inhibits chondrocyte differentiation through PKA and PKC signaling. Exp Cell Res 300: 159-169.

Linsenmayer TF, Eavey RD, Schmid TM (1988) Type $\mathrm{X}$ collagen: a hypertrophic cartilage-specific molecule. Pathol Immunopathol Res 7: 14-19.

Mackie EJ, Ahmed YA, Tatarczuch L, Chen KS, Mirams M (2008) Endochondral ossification: how cartilage is converted into bone in the developing skeleton. Int $\mathrm{J}$ Biochem Cell Biol 40: 46-62.

Nagayama M, Iwamoto M, Hargett A, Kamiya N, Tamamura Y, Young B, Morrison T, Takeuchi H, Pacifici M, Enomoto-Iwamoto M, Koyama E (2008) Wnt/betacatenin signaling regulates cranial base development and growth. J Dent Res 87: 244-249.

Naik AA, Xie C, Zuscik MJ, Kingsley P, Schwarz EM, Awad H, Guldberg R, Drissi H, Puzas JE, Boyce B, Zhang X, O’Keefe RJ (2009) Reduced COX-2 expression in aged mice is associated with impaired fracture healing. $\mathrm{J}$ Bone Miner Res 24: 251-264.

O’Driscoll SW, Recklies AD, Poole AR (1994) Chondrogenesis in periosteal explants. An organ culture model for in vitro study. J Bone Joint Surg Am 76: 10421051.

Petit A, Wang HT, Girard-Lauriault PL, Wertheimer MR, Antoniou J, Mwale F (2010) Novel insights into the mechanism of decreased expression of type $\mathrm{X}$ collagen in human mesenchymal stem cells from patients with osteoarthritis cultured on nitrogen-rich plasma polymers: implication of cyclooxygenase-1. J Biomed Mater Res A 94: 744-750.

Shui C, Spelsberg TC, Riggs BL, Khosla S (2003) Changes in Runx2/Cbfa1 expression and activity during osteoblastic differentiation of human bone marrow stromal cells. J Bone Miner Res 18: 213-221.

Simon AM, O'Connor JP (2007) Dose and timedependent effects of cyclooxygenase-2 inhibition on fracture-healing. J Bone Joint Surg Am 89: 500-511.

Steinert AF, Proffen B, Kunz M, Hendrich C, Ghivizzani SC, Noth U, Rethwilm A, Eulert J, Evans $\mathrm{CH}$ (2009) Hypertrophy is induced during the in vitro chondrogenic differentiation of human mesenchymal stem cells by bone morphogenetic protein-2 and bone morphogenetic protein-4 gene transfer. Arthritis Res Ther 11: R148.

Thaller J, Walker M, Kline AJ, Anderson DG (2005) The effect of nonsteroidal anti-inflammatory agents on spinal fusion. Orthopedics 28: 299-303; quiz 304-295.

Ulivi V, Giannoni P, Gentili C, Cancedda R, Descalzi F (2008) p38/NF-kB-dependent expression of COX-2 during differentiation and inflammatory response of chondrocytes. J Cell Biochem 104: 1393-1406.

Xie C, Liang B, Xue M, Lin AS, Loiselle A, Schwarz EM, Guldberg RE, O'Keefe RJ, Zhang X (2009) Rescue of impaired fracture healing in COX-2-/- mice via activation of prostaglandin E2 receptor subtype 4. Am J Pathol 175: 772-785.

Yamakawa K, Kamekura S, Kawamura N, Saegusa M, Kamei D, Murakami M, Kudo I, Uematsu S, Akira S, Chung UI, Nakamura K, Kawaguchi H (2008) Association of microsomal prostaglandin E synthase 1 deficiency with impaired fracture healing, but not with bone loss or osteoarthritis, in mouse models of skeletal disorders. Arthritis Rheum 58: 172-183.

Zhang X, Schwarz EM, Young DA, Puzas JE, Rosier RN, O'Keefe RJ (2002) Cyclooxygenase-2 regulates mesenchymal cell differentiation into the osteoblast lineage and is critically involved in bone repair. J Clin Invest 109: 1405-1415.

Zheng Q, Zhou G, Morello R, Chen Y, Garcia-Rojas X, Lee B (2003) Type X collagen gene regulation by Runx2 contributes directly to its hypertrophic chondrocytespecific expression in vivo. J Cell Biol 162: 833-842.

\section{Discussion with Reviewers}

Reviewer I: The mRNA expression data are expressed as fold increase relative to day 0 of differentiation. On day 0 the differentiation genes would be not expressed, or have a very very low expression. Therefore, day 0 is unsuitable to use since it is not very precise. Please comment.

Authors: When mRNAs are not or very very lowly expressed at day 0 , the reviewer is correct that this way of presenting the qPCR data would be unsuitable. However, the models we used include chondroprogenitor cells that always display basal mRNA expression levels of the important endochondral genes at day 0. QPCR analyses of these genes on day 0 -samples generally shows average CT values of 25 . This indicates that indeed basal mRNA 
expression of these genes is low, but is not absent. This can also be found back in the levels of the fold increases in the graphs throughout the manuscript: if expression of these genes at day 0 would be very low or absent, the relative expression would increase thousands of times upon initiation of differentiation. Although relative induction of mRNA expression upon chondrogenic differentiation is robust (as one would expect for initiation of a chondrogenic differentiation program starting from a chondroprogenitor stage), the relative increase is within the range described in literature on chondroprogenitor cells. As we confirmed a low basal expression of the important chondrocyte genes in the cell models at day 0 and a similar way of presenting such data is also used in literature (e.g., Gaur et al., 2006; L. Chen et al., 2011; W. Chen et al. 2011; additional references), we maintained the current way in which the qPCR data are presented.

Reviewer I: Had the length of the bones of the rabbits with celecoxib changed?

Authors: The question is whether the effect on chondrocyte hypertrophic differentiation in the growth plate also causes long term skeletal effects. The rabbit experiment presented here was a pilot experiment in which the prime question was focused on the development of the growth plate itself. Consequently, at the time of the experiment, we did not determine the length of the bones. As all tissues have been processed this is also not possible anymore.
Reviewer I: A smaller hypertrophic zone in the growth plate could also indicate fast endochondral ossification. It is a pity the growth plates were decalcified otherwise staining for calcification would have been possible to obtain additional insights.

Authors: We agree that a more extensive calcification analysis in these growth plates would have been insightful. We will address this question in a follow-up study where we are planning to address the effect of COX-2 inhibition on skeletal development on the longer term.

\section{Additional References}

Chen L, Qanie D, Jafari A, Taipaleenmaki H, Jensen CH, Säämänen AM, Nueda Sanz ML, Laborda J, Abdallah BM, Kassem M (2011) Delta-like 1/fetal antigen-1 (Dlk1/FA1) is a novel regulator of chondrogenic cell differentiation via inhibition of the Akt kinase-dependent pathway. J Biol Chem 286: 32140-32149.

Chen W, Zhang X, Siu, RK, Chen F, Shen J, Zara JN, Culiat CT, Tetradis S, Ting K, Soo C (2011) Nfatc2 is a primary response gene of Nell-1 regulating chondrogenesis in ATDC5 cells. J Bone Mineral Res 26: 1230-1241.

Gaur T, Rich L, Lengner CJ, Hussain S, Trevant B, Ayers D, Stein JL, Bodine PV, Komm BS, Stein GS, Lian JB (2006) Secreted frizzled related protein 1 regulates Wnt signaling for BMP2 induced chondrocyte differentiation. J Cell Physiol 208: 87-96. 